\title{
Comparative Optical Measurements of Airspeed and Aerosols on a DC-8 Aircraft
}

Rodney Bogue

NASA Dryden Flight Research Center

Edwards, California

Rick McGann

Boeing Defense \& Space Group

Seattle, Washington

Thomas Wagener

Honeywell Systems Research Center

Minneapolis, Minnesota

John Abbiss

Singular Systems

Irvine, California

Anthony Smart

Titan Corporation

Costa Mesa, California

1997

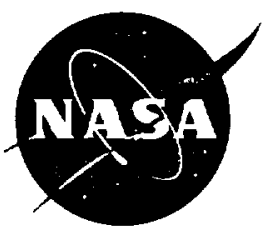

National Aeronautics and

Space Administration

Dryden Flight Research Center

Edwards, California 93523-0273 



\title{
Comparative Optical Measurements of Airspeed and Aerosols on a DC-8 Aircraft
}

\author{
Rodney Bogue \\ NASA Dryden Flight Research Center \\ Edwards, California \\ Rick McGann \\ Boeing Defense \& Space Group \\ Seattle, Washington \\ Thomas Wagener \\ Honeywell Systems Research Center \\ Minneapolis, Minnesota \\ John Abbiss \\ Singular Systems \\ Irvine, California \\ Anthony Smart \\ Titan Corporation \\ Costa Mesa, California
}

\begin{abstract}
NASA Dryden supported a cooperative flight test program on the NASA DC-8 aircraft in November 1993. This program evaluated optical airspeed and aerosol measurement techniques. Three brassboard optical systems were tested. Two were laser Doppler systems designed to measure freestream-referenced airspeed. The third system was designed to characterize the natural aerosol statistics and airspeed. These systems relied on optical backscatter from natural aerosols for operation. The DC-8 aircraft carried instrumentation that provided real-time flight situation information and reference data on the aerosol environment. This test is believed to be the first to include multiple optical airspeed systems on the same carrier aircraft, so performance could be directly compared. During $23 \mathrm{hr}$ of flight, a broad range of atmospheric conditions was encountered, including aerosol-rich layers, visible clouds, and unusually clean (aerosol-poor) regions. Substantial amounts of data were obtained. Important insights regarding the use of laser-based systems of this type in an aircraft environment were gained. This paper
\end{abstract}

describes the sensors used and flight operations conducted to support the experiments. The paper also briefly describes the general results of the experiments.

\section{INTRODUCTION}

Four test flights on the NASA DC-8 aircraft were completed in November 1993 at Ames Research Center, Moffett Field, California. The DC-8 was manufactured by the McDonnell Douglas Aircraft Company, Long Beach, California. Three brassboard optical systems were tested during the program. Two were laser Doppler systems designed to measure free-streamreferenced airspeed. One system was designed to measure natural aerosols and airspeed. Doppler airspeed and aerosol measurement technologies have applications for propulsion system inlet unstart warning and gust alleviation for the High Speed Civil Transport (HSCT), for subsonic aircraft, and for environmental assessment in the troposphere and stratosphere. In addition, this technology has broad application for measuring airspeed for high-performance military aircraft and rotorcraft. 
The two Doppler systems are based on measuring the Doppler frequency shift in laser light reflected from natural aerosols present in the atmosphere. Each of the two Doppler systems used a different combination of wavelength $(1.06 \mu \mathrm{m}$ and $2.01 \mu \mathrm{m})$, operating mode (continuous wave (CW) and pulsed), and focal distance ( $1 \mathrm{~m}$ to $47 \mathrm{~m}$ ). One system was developed by Boeing Defense \& Space Group, Seattle, Washington. The concept is termed the Enhanced Mode Lidar (EML) for which a patent has been issued. In this document, the generic terminology "continuous wave Doppler (CD) lidar" is used when referencing this system.

The other Doppler system was jointly fielded through a cooperative effort by Honeywell Systems Research Center, Minneapolis, Minnesota, and Lightwave Electronics, Mountain View, California. The Doppler lidar was developed by Lightwave Electronics under a Small Business Innovative Research contract. Honeywell developed the signal processing capability and performed the system integration. This concept and the resulting system is termed pulsed Doppler (PD) lidar.

The airspeed and aerosol measurement system, developed by Titan Corporation, Costa Mesa, California, used a pair of light sheets and a correlation process to identify and measure atmospheric particles and the transit time of these particles between the light sheets. Particle size distribution and airspeed were computed from these inputs. This concept, and the resulting system, is referred to as the sheet-pairs system. Because each system operates on aerosol backscatter, separate reference aerosol measurement probes were installed to document the aerosol environment. Each experimental system was provided with the DC-8 flight conditions from the onboard information bus.

During these tests, three systems using different parameters were concurrently evaluated. This approach removes one of the major variables, atmospheric aerosol environment, from the test matrix and allows a direct performance comparison under identical conditions. This paper describes the sensors used and flight operations conducted in support of the experiments. General results of the experiments are also briefly described.
During the $23 \mathrm{hr}$ of flight, a broad range of atmospheric conditions was encountered. These conditions included aerosol-rich layers, visible clouds, and unusually clean (aerosol-poor) regions. Some test systems were operational for the entire flight. All systems were operating for a substantial portion of the flights. Substantial amounts of data were obtained, and an important insight was gained regarding the use of laser-based systems of this type in an aircraft environment.

\section{AIRCRAFT DESCRIPTION}

A DC-8 commercial transport powered by four CFM-56 high-bypass, turbofan jet engines served as the testbed aircraft for this series of tests. The turbofan engines were manufactured by the General Electric Company, Cincinnati, Ohio. Table 1 provides key information about the aircraft characteristics and performance [1].

The NASA DC-8 airplane has been modified to create a laboratory environment in flight to support a wide variety of tests. This airplane is operated for the benefit of researchers from a broad spectrum of

Table 1. NASA DC-8 airborne laboratory summary characteristics and performance data.

\begin{tabular}{|c|c|}
\hline Crew & $\begin{array}{l}\text { Two pilots, one flight engineer, one } \\
\text { navigator }\end{array}$ \\
\hline Length & $157 \mathrm{ft}(47.9 \mathrm{~m})$ \\
\hline Wingspan & $148 \mathrm{ft}(45.1 \mathrm{~m})$ \\
\hline Engines & $\begin{array}{l}\text { Four CFM 56-2-C1 high-bypass, tur- } \\
\text { bofan jet }\end{array}$ \\
\hline Base & $\begin{array}{l}\text { Ames Research Center, Moffett Field, } \\
\text { California }\end{array}$ \\
\hline Altitude & $0-41,000 \mathrm{ft}(12,500 \mathrm{~m})$ \\
\hline Range & 5400 n.m. $(10,000 \mathrm{~km})$ \\
\hline Duration & $12 \mathrm{hr}$ \\
\hline Speed & $\begin{array}{l}425-490 \mathrm{kn} \text { true airspeed (cruise) } \\
(219-252 \mathrm{~m} / \mathrm{sec})\end{array}$ \\
\hline Payload & $30,000 \mathrm{lb}(13,640 \mathrm{~kg})$ \\
\hline
\end{tabular}


organizations. Projects typically include activities in atmospheric and space sciences, technology applications, climatology, Earth resources, and aeronautics.

The DC-8 airplane has an extensive set of supporting systems designed to provide corroborating measurements in support of test programs. The Data Acquisition and Distribution System (DADS) and the Particle Measurement System (PMS) were operating in direct support of the airspeed experiments although many other systems were operational during the DC-8 flight test. The DADS employs a central computer system on the aircraft to gather information from the standard aircraft and research support systems. This information is processed into engineering units and distributed in real time to each test station through a standard serial data communication channel.

For this series of tests, DADS was heavily used by all experimenters to correlate test results with time and flight conditions. In addition, a closed-circuit television system was used to display flight parameters, research support data, or video camera imaging in real time. Television monitors were mounted at test stations to coordinate the various research test activities. Table 2 provides a partial list of the available parameters on the DADS.

Optical systems on this flight test series depend heavily upon the ambient aerosol environment. The PMS provided independent measurement of number density and size distribution of the aerosols found in the vicinity of the DC-8 airplane during the flight test.

Table 2. Partial data acquisition and distribution system parameter list.

\begin{tabular}{cc}
\hline \hline Airspeed & $\begin{array}{c}\text { Altitude: } \\
\text { radar pressure }\end{array}$ \\
Dew point & Humidity \\
Latitude & Longitude \\
Pitch angle & Pitch rate \\
Roll angle & Roll rate \\
Sun angle & Universal time \\
Yaw angle & Yaw rate \\
\hline \hline
\end{tabular}

Table 3 lists the three particle-measurement-sensing systems which were operating on the aircraft.

A real-time readout of the PMS information was available during each DC-8 flight. This readout provided an assessment of the aerosol environment. A choice of averaging times together with comparisons between fresh data and recently acquired averages to ascertain departures from long-term averages was available.

\section{AEROSOL MEASUREMENT}

The presence of multiple variables makes characterization of the aerosol environment complex. The set of variables includes aerosol number density, size distribution, mass density, chemical and structural composition, shape, and optical refraction index. This task is strongly based on statistical concepts and is highly dependent on data accumulation time, short-term spatial and temporal aerosol density variations, and calibration of the measurement equipment. The atmospheric science community generally accepts FSSP-300 sensors as the standard for in-flight aerosol measurement. These sensors served as the standard for these tests.

\section{Particle Measurement System Probe Operation}

The PMS included three particle sensors. The operation of the FSSP-300 spectrometer probe (two of the three installed probes) is described here. The sensor relies on aerosol-scattered light from a visible laser to measure individual particles flowing through the focused laser beam. Laser light is forward-scattered from the aerosols in the beam onto photo detectors calibrated to provide individual particle size information. Aerosol-scattered light depends upon the size, shape, and refraction index of the target aerosol. The sensor provides size information based on the Miescattering theory and assumes a spherical aerosol shape and a refraction index value. The FSSP-300 sensors were calibrated by passing microscopic spheres of known diameter and refraction index through the sensor.

The system has several size ranges or "bins" into which the particle count for each range is accumulated. As the sensor moves by the aircraft motion through the region of the atmosphere to be measured, 
Table 3. Particle measurement system locations and performance specifications.

\begin{tabular}{ccccc}
\hline System & Model & Aerosol Size & Resolution & $\begin{array}{c}\text { Measurement } \\
\text { Location }\end{array}$ \\
\hline 1 & FSSP-300 & $0.3-20 \mu \mathrm{m}$ & 31 ranges & Left wingtip \\
2 & FSSP-300 & $0.3-20 \mu \mathrm{m}$ & 31 ranges & Right wingtip \\
3 & PCASP-100X & $0.1-3 \mu \mathrm{m}$ & 15 ranges & Left wingtip \\
\hline
\end{tabular}

the number of particles within a size range is accumulated into each respective bin. After a specified measurement interval, bin counts are electronically returned to zero, and the accumulation of counts begins anew. To ensure measurement accuracy, the internal optical measurement area is quite small. As a result, even with a velocity on the order of $200 \mathrm{~m} / \mathrm{sec}$, the effective volume "swept out" per unit time is quite small (12 mL/sec for a velocity of $200 \mathrm{~m} / \mathrm{sec}$ ).

For a bin measurement to be considered valid, a statistically significant number of counts must be accumulated. The combined small swept volume and the statistical requirements often dictate extended accumulation times, particularly when the aerosol density is low. The FSSP-300 system may require measurement times on the order of 1 to 10 's of minutes for statistically reliable measurement, corresponding to a horizontal distance of many kilometers.

\section{Aerosol Backscatter Characterization}

For the experiments on this series of flight tests, the important parameter was the light energy reflected (or backscattered) back to the source from the natural aerosols. Figure 1 shows the relationship between the average scattering coefficient, averaged over a measurement aperture, of an individual particle as a

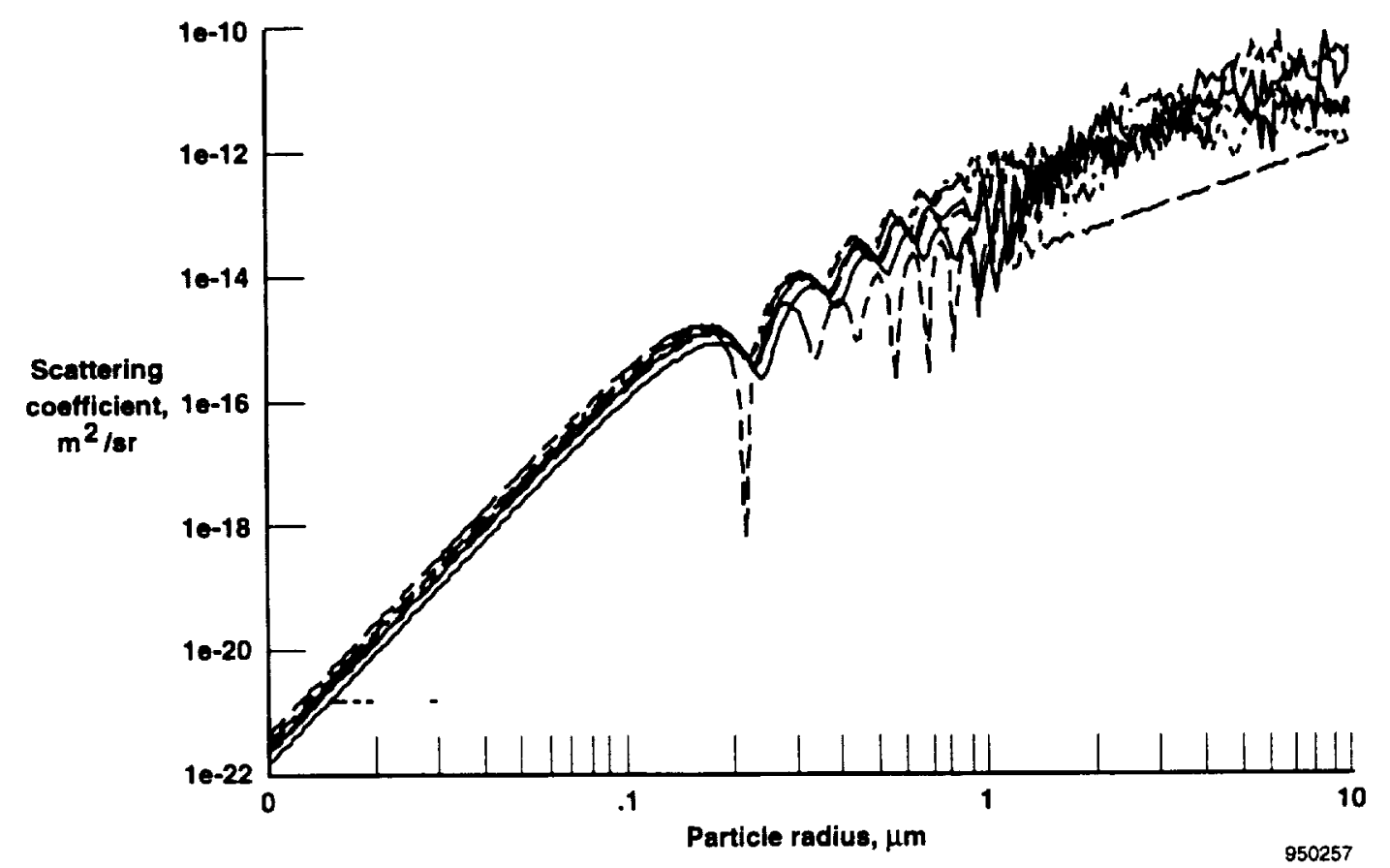

Figure 1. Calculated scattering properties at $0.810 \mu \mathrm{m}$ integrated over the sheet-pairs aperture for typical airborne aerosol materials. 
function of particle radius for a wavelength of $0.810 \mu \mathrm{m}$. The $0.810-\mu \mathrm{m}$ wavelength and the measurement aperture for figure 1 were those used in the sheet-pairs flight system and represents the expected return for that system [2] [3].

The aperture average represents the integrated specific particle-scattering pattern over the solid angle subtended by the aperture through which the scattered energy passes divided by the subtended solid angle. The scattering coefficient is expressed as an equivalent scattering area per unit solid angle. The multiple curves represent the response for a variety of common particles, including rural and maritime aerosols, sea salt, and sulfuric acid droplets. Acid droplets are a primary stratospheric aerosol constituent resulting from volcanic activity.

When the wavelength of the light is much longer than the particle radius, the response is well-behaved as illustrated by the response to the left of the $0.1-\mu \mathrm{m}$ radius position (fig. 1). When the wavelength of the scattered light is of the same order of magnitude as the size of the scattering particles, the process becomes substantially more complex and nonlinear. Light scattered under these conditions requires a complete Miescattering analysis and is illustrated by the region of the response curve to the right of the $0.1-\mu \mathrm{m}$ radius position. Although the trend for the scattering coefficient is in the same general direction, the value for any particle size, particularly for particles having a radius from $0.6 \mu \mathrm{m}$ to beyond $1 \mu \mathrm{m}$, can vary as much as two orders of magnitude or more for only a small change in particle radius.

Optical atmospheric scattering is characterized by a scattering parameter $(\beta)$. The $\beta$ varies with observation angle and is the ratio of reflected energy to emitted energy scaled by the included solid angle of the observation optics (steradians) and the optical depth of the region from which the energy is being scattered (meters). The $\beta_{\pi}$ is the scattering parameter at an observation angle of $\pi$ which is the angle for scattering energy that is returned to the transmitter (back-scatter).

Aerosol backscatter was measured using two methods. One directly measured the backscattered energy received. This measurement was then used along with the transmitted energy level to calculate the integrated backscatter coefficient, $\beta_{\pi}$, value. The other method used an algorithm to compute the $\beta_{\pi}$ value based on aerosol number density and size distribution measurements from the onboard PMS.

For conventional lidar measurements, the important scattering information is represented by $\beta_{\pi}$ obtained from ensembles of particles that occupy the sensitive volume from which light is reflected back to the transmitter. In theory, if the number density and aerosol size distribution were precisely known, it would be possible to compute a $\beta_{\pi}$ value by using figure 1 to calculate the contribution of the individual particles and to then sum these values to arrive at a $\beta_{\pi}$ value.

Considering the figure 1 curve, however, this approach is subject to substantial error for even a small uncertainty in either the size distribution or number density. Given the uncertainties in measuring the particle characteristics and number density, uncertainty in the computation of a $\beta_{\pi}$, and long measurement accumulation time, the computed value probably will not correlate well with directly measured instantaneous $\beta_{\pi}$ values acquired in the same time window.

\section{EXPERIMENTAL SYSTEMS OPERATING CHARACTERISTICS}

Two of the experimental systems used modified versions of the classical lidar operating concept. The classical lidar concept projects a pulsed, collimated laser beam into the atmosphere. The time delay between beam transmission and reception of the backscattered signal (also called range gating) is used to select the target distance, or the range from which the backscattered signal is derived.

An ensemble of aerosols provides the diffuse target for the pulsed lidar system. By analyzing the characteristics of the backscattered signal, the concentration and speed of atmospheric aerosols may be obtained. Speed of the aerosols is determined along the axis of the projected beam by measuring the Doppler frequency shift between the projected and backscattered signals. Aerosol concentration is obtained by analyzing the intensity distribution of the backscattered signal. Both of the experimental Doppler lidar systems were different from the classical concept in that beam focusing, as opposed to range gating, was used to 
select the range from which the backscattered signal was obtained. One of the experimental Doppler lidar systems departed in another way from the classical concept by using a continuous wave laser.

The third experimental system used a particle transit concept to measure the time of flight of aerosols between pairs of laser sheets projected into the atmosphere. Unlike the lidar, this approach obtained the aerosol speed component perpendicular to the plane of the projected sheet-pair.

The continuous wave Doppler system used a continuous wave laser source focused to a small focal region. This system was designed to operate on the backscattered signal from single particles as they transit the small focal volume. Single particle backscatter, as opposed to backscatter from an ensemble of particles, is the basic tenant of the EML concept and has the advantage of a high signal-to-noise ratio (SNR). This increase in SNR is traded off against a decrease in range and particle dwell time in the small focal volume that may contribute to increased scatter in the data when the focal volume is extremely small.

The pulsed Doppler system was designed to operate on the backscattered signal from an ensemble of aerosols, much like the conventional concept. The pulsed mode of operation was used to increase the peak power available in the focal region and, thereby, increase the backscattered signal level to improve the SNR. To a first-order level of analysis, the amplitude of the backscattered signal is independent of the focal distance. In addition, range and performance of the system are nearly independent of the focal distance until that distance becomes so large that the beam is effectively collimated. Then, the operation merges with the conventional lidar approach.

The sheet-pairs system airspeed measurement is based on a time-of-flight approach that is a completely different operating concept from the Doppler lidar. A light sheet pair with accurately known separation distance is projected into the flow field of interest. Individual particles are detected as they transit each sheet pair. The transit time of the aerosols is measured by a sophisticated correlation process from which the aerosol velocity is determined using the sheet separation distance. The particle measurement concept used backscattered light intensity and sheet dwell time for individual particles to estimate the aerosol size.

\section{SYSTEM INSTALLATION}

Figure 2 shows the layout of experiments on the DC- 8 aircraft. The lines with arrows show the direction and focal distance of the laser beams used to acquire the lidar data. Aircraft station numbers originate at the nose. These station numbers are shown between the side and vertical perspectives. Line dimensions are noted in meters. The aircraft windows are removable. Either the window or a modified installation was used as the optical port for the laser.

The continuous wave Doppler system was installed on the right side of the aircraft using the window located near station 520 with the laser making an angle of $75.6^{\circ}$ with the $x$-axis of the aircraft. The pulsed Doppler system was installed on the left side of the aircraft using the window located near station 570 . The laser for this system was projected at an angle of $45^{\circ}$ with the aircraft $x$-axis.

The sheet-pairs system was located on the left side of the aircraft with the experiment using the station 445 window. The beams from the sheet-pairs system were projected at a $90^{\circ}$ angle from the fuselage, but the sensitive measurement direction was orthogonal to the beams. As a result, the system was aligned directly parallel with the aircraft x-axis. Figure 2 does not show the sheet-pairs chiller that was installed in the forward cargo bay under the cabin area between stations 270 and 640 .

\section{CONTINUOUS WAVE DOPPLER SYSTEM DESCRIPTION}

The continuous wave Doppler lidar was developed to augment pitot-static-based systems with a state-ofthe-art optical airspeed sensor system with the ability to measure true airspeed (TAS), angle of attack, and angle of sideslip outside of the influence of the airplane flow field. Before development of the current system, conventional CW or pulsed Doppler lidar systems were used. Previous systems required large, inefficient laser sources to achieve the power needed to maintain acceptable data rates under "clear air" (low aerosol density) atmospheric conditions. Unlike some earlier systems, this one is built around a diodepumped, solid-state laser. 


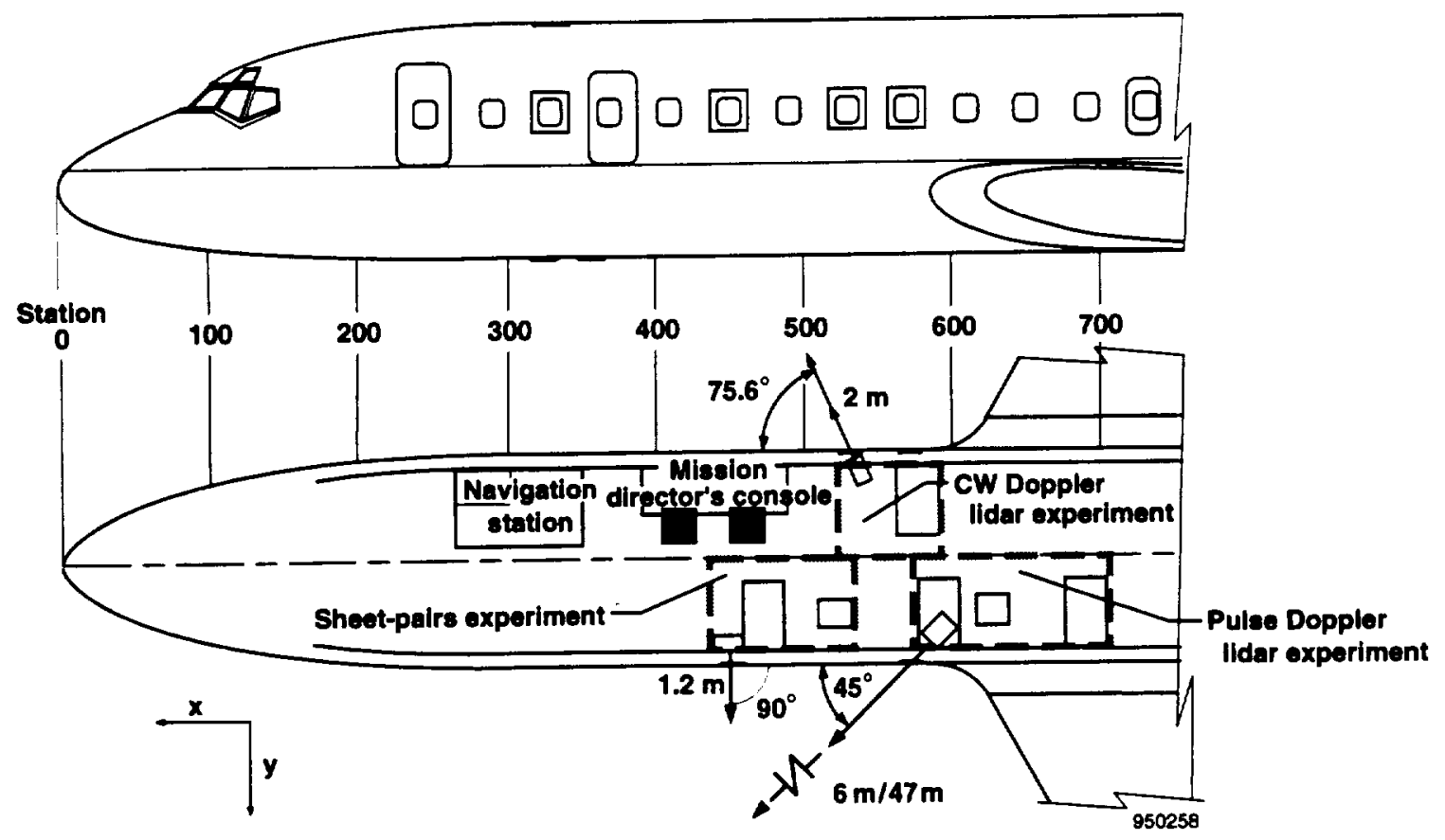

Figure 2. Arrangement of experiments on the DC-8 aircraft.

For the past 5 yr, Boeing Defense \& Space Group has been improving the EML concept for use as a line-of-sight optical airspeed sensor [4] [5]. Initial development included tests in a controlled environment where the ambient particle size distribution was carefully monitored. A performance model was developed, and the test data were used to validate the predictions over a broad range of particle size distributions and backscatter conditions.

Successful velocity measurement demonstrations were performed in wind-tunnel flow fields (with and without particulate seeding) and in local wind conditions using natural aerosol populations. Twelve hours of flight testing over the course of three flights were completed onboard a University of Washington Convair $\mathrm{C}-131 \mathrm{~A}$ testbed aircraft before the tests described in this document [4].

\section{Theory of Operation}

For a conventional heterodyne lidar, the SNR of the signal returned from the atmosphere is given in reference 6 as

$$
\mathrm{SNR}=\frac{\eta \mathrm{P}_{\mathrm{o}} \beta_{\pi} \lambda^{2} F}{2 h c B}
$$

where $\eta$ is the system efficiency, $P_{0}$ is the laser output power, $\beta_{\pi}$ is the backscatter coefficient, $\lambda$ is the laser wavelength, $B$ is the signal bandwidth, $h$ is Planck's constant, $c$ is the speed of light, and $F$ is a factor that depends on the range and $f$-number. For this configuration, $F$ is approximately equal to $\pi$.

The atmospheric $\beta_{\pi}$ (meter $^{-1}$ steradian $^{-1}$ ) is the integrated product of individual particle-scattering coefficients and the number density of atmospheric particles. The conventional lidar expression for the SNR is valid only when many particles are simultaneously present in the detection volume at the focus of the output beam. In this regime, average signal power is nearly independent of focus. As the signal per particle increases with sharper focusing, the number of particles in the detection volume decreases proportionately, thereby increasing the backscattered signal variability.

The EML concept exploits the fact that as the beam is focused to a small focal volume (fig. 3), obtaining a retum signal from discrete particles is possible. This signal is much greater than that predicted by the conventional lidar signal power equation. Performance of a lidar in the limit of intermittence (that is discrete rather than continuous detection) can be described by 


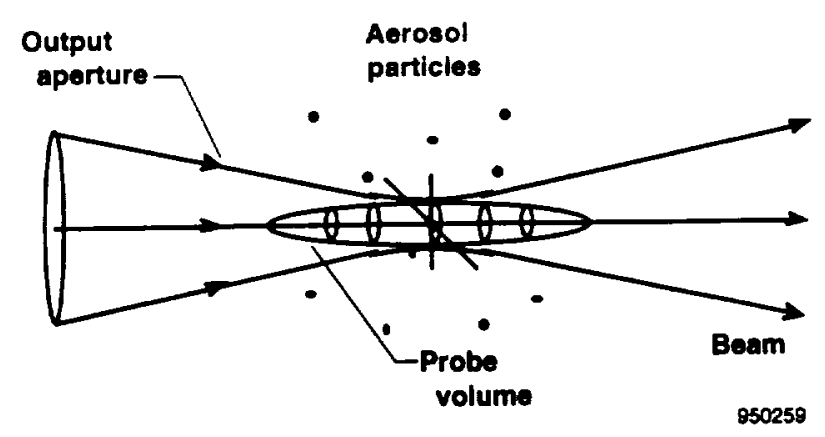

Figure 3. Detection volume geometry.

calculating the SNR of a single particle in the center of the beam. For example,

$$
\mathrm{SNR}_{\mathrm{EML}}=\frac{\pi \eta \mathrm{P}_{\mathrm{o}} \sigma}{256 \lambda B h c(\mathrm{f})^{4}}
$$

where $\sigma$ is the scattering cross-section of the particle, and $f$ is the $f$-number of the system. The strong ( $\left.1 / f^{4}\right)$ dependence on the system $f$-number provides a large gain in the backscattered signal for a small system f-number. The small $f$-number is obtained by using a short-range focal distance with a large diameter lens.

The relationship between $\beta_{\pi}$ and $\sigma$ can be approximated by

$$
\beta_{\pi}=\frac{\sigma \rho}{4 \pi}
$$

where $\rho$ is the number density of hypothetical particles having single backscatter cross-sections $\sigma$.

The gain in the signal over a conventional or longrange lidar can then be approximated by the ratio of the enhanced and conventional return signal given by

$$
\frac{\mathrm{SNR}_{\mathrm{EML}}}{\mathrm{SNR}_{\mathrm{CONV}}}=\frac{16}{\pi \rho \mathrm{V}}
$$

where $\mathrm{V}$ is the volume of the focus of the laser beam to the $1 / \mathrm{e}^{2}$ points in the radial direction and to approximately the Rayleigh range in the axial direction. The Rayleigh range is defined as $\pi \omega_{0}^{2} / \lambda$. The $\omega_{0}$ is the diameter of the focal volume, and $\lambda$ is the wavelength of the light.

Under these conditions, particles pass individually through the detection volume (fig. 3). Each time a particle is present, a signal pulse of high SNR is received. This condition allows for the use of a much lower power laser compared to a conventional lidar system. Using lower power is a viable option when the required sensing range is limited, and the aerosol density is high enough to provide an adequate data rate (sufficient rate of aerosols transiting the focal region). Large particles in the focal region increase the signal level and partially offset the range limitation. The signal power retumed from the individual particles is constant for a given size particle regardless of the number density.

\section{Optical Overview}

Figure 4 shows the optical configuration of the CD brassboard sensor. The brassboard employs a small, efficient, commercially available, diode-pumped, solid-state Nd:YAG laser with a $500-\mathrm{mW}$ output power and a wavelength of $1.064 \mu \mathrm{m}$. Optics and hardware components in the brassboard consist of commercially available off-the-shelf items. Although the brassboard was not designed for minimum size or weight, the optical head measures only $7.5 \times 17.5 \times$ $27.5 \mathrm{~cm}$ and weighs less than $5 \mathrm{~kg}$. The output aperture is $50 \mathrm{~mm}$, and the final $\mathrm{f}$-number of the system can be adjusted by changing the output lens. Performance was evaluated for 1 - and $2-\mathrm{m}$ focal length corresponding to operation at $f / 20$ and $f / 40$, respectively. The photodetector is a commercially available indium gallium arsenide (InGaAs) detector integrated into a detector/amplifier package.

\section{Processor Overview}

The resulting signals from the InGaAs detector/ amplifier were processed with a high-speed burst signal processor. This device uses a multilag, autocorrelation system to trigger on the presence of a detectable particle in 16 subbandwidths to increase triggering sensitivity. A 256-sample autocorrelation function is then calculated with a bandwidth of $90 \mathrm{MHz}$ [7]. Calculation of the autocorrelation and signal center frequency are performed internally. In addition, the 


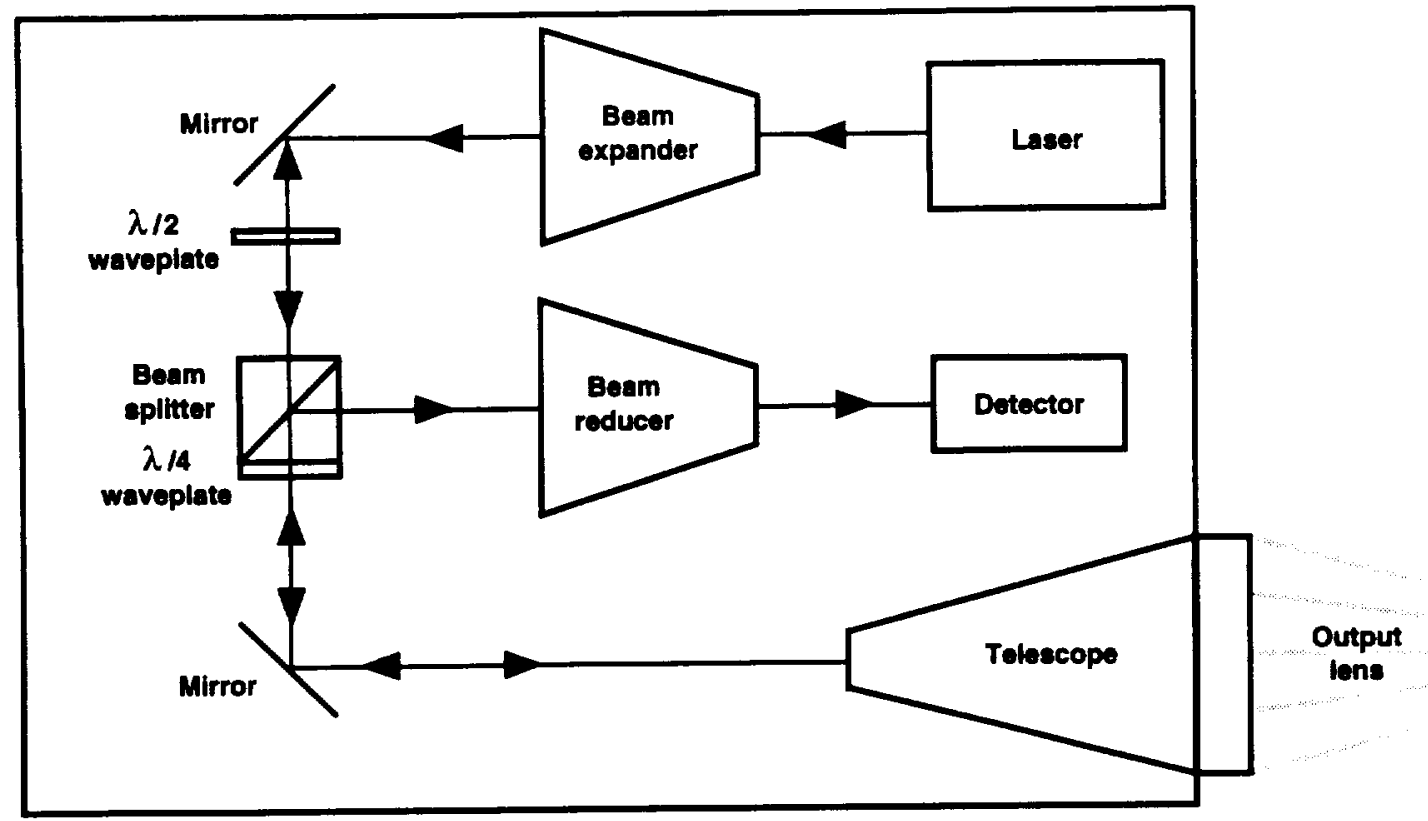

850260

Figure 4. Continuous wave Doppler lidar brassboard configuration.

signal frequency and a time stamp are passed through a data bus to a computer for storage.

System information was transferred and digitized in a parallel data stream by independently triggering a high-frequency storage oscilloscope and storing individual bursts and strings of raw data. The high-rate digitized data acquired and stored during the flight test permits controlled postflight evaluation, optimization, and validation of airspeed detection algorithms.

\section{PULSED DOPPLER SYSTEM DESCRIPTION}

This pulsed Doppler lidar was flight tested to demonstrate the maturity of the diode-pumped, $2-\mu \mathrm{m}$, solid-state laser technology for airspeed measurement and to correlate the $\beta_{\pi}$ from $2-\mu \mathrm{m}$ pulsed Doppler lidars with that predicted using optical PMS. To the authors' knowledge, this was the first successful flight test of a 2- $\mu \mathrm{m}$ Doppler lidar for airspeed measurements. This test represents the only direct airborne (up to $40 \mathrm{kft}$ ) measurement of $\beta_{\pi}$ at $2 \mu \mathrm{m}$ and the subsequent comparison with $\beta_{\pi}$ derived from the optical PMS. The $0.75-\mathrm{mJ}$ output power, and $0.75-\mu \mathrm{sec}$ pulse length of this lidar were appropriate for airdata, wind shear, and wake vortex detection, but they were somewhat low for clear air turbulence and other high-altitude long-range measurements. Less than $300 \mathrm{~W}$ was needed to operate the lidar with no water cooling. The Tm:YAG laser technology at $2 \mu \mathrm{m}$ was selected because of its eye-tolerant characteristics in accordance with ANSI standard Z136.1-1993.

\section{Theory of Operation}

This 2- $\mu \mathrm{m}$ pulsed Doppler lidar is based on the pulsed-heterodyne Doppler technique. This technique is a true heterodyne system in the sense that the local oscillator was continuously offset-tuned to the outgoing pulse frequency. The detection method used light focused at a short range with the measurement volume determined by the coherency criterion. This method provides maximum SNR. The light was focused at a distance between 6 and $47 \mathrm{~m}$ using a 12.7-mm aperture.

The relatively large measurement volume relies on the scattering from multiple particles that exist in the volume. The lidar system was optimized for this measurement regime. The advantage of this approach is that an accurate velocity measurement (to better than $1 \mathrm{~m} / \mathrm{sec}$ ) is taken outside the aircraft local flow field. The disadvantage is that a sophisticated high-pulse energy coherent laser must be used. 


\section{Optical Summary}

Figure 5 shows the optical schematic of the $2-\mu \mathrm{m}$ PD lidar used in these flight tests. Optical paths between components were accomplished using optical fibers and fiber couplers. No adjustable optical mounts were used in its construction. Performance and alignment were not affected by several crosscountry trips by truck or by installation in the airplane.

A coherent CW Tm:YAG laser was used to injection seed the Q-switched oscillator. The output of the Q-switched oscillator is, therefore, at the frequency of the injection seed laser but shifted by $54 \mathrm{MHz}$ because of the acousto-optic modulator. The acousto-optically Q-switched laser produced $0.75-\mathrm{mJ}, 750-\mathrm{nsec}$ pulses in a diffraction-limited beam at a $600-\mathrm{Hz}$ repetition rate. The output of the Q-switched oscillator is scattered from atmospheric aerosols, and the returned light is optically mixed with the local oscillator laser. The result is a Doppler intermediate frequency (IF) signal proportional to the velocity of the aerosols. A second coherent CW Tm:YAG laser was used as the local oscillator. The two $\mathrm{CW}$ lasers were frequency offset using a laser offset locking accessory (LOLA). Additional details regarding the $2-\mu \mathrm{m}$ Doppler lidar can be found in references 8 and 9 .

\section{Processor Overview}

Figure 6 shows the integrated lidar system. The personal computer based control and data acquisition included real-time LOLA control, lidar monitoring using pulse build-up time as a discriminator, data acquisition and storage, $80-\mathrm{dB}$ range digital gain control, and real-time graphical display of lidar and aircraft data. Data from up to 50 pulses/sec could be stored. After each flight, these data were copied onto a tape drive for storage and further analysis.

\section{SHEET-PAIR TRANSIT TIME SYSTEM DESCRIPTION}

The original sheet-pairs system measured three independent velocity components from which TAS could be computed. The velocity was measured $1.2 \mathrm{~m}$ from the aircraft surface. The system flown on the DC-8 program was modified to provide one velocity component and to yield an estimate of the energy scattered into the receiver by particles contributing to the velocity measurements.

This arrangement allowed improved use of the system data processing capacity. The arrangement also permitted an increased number of particles to be processed. The instrument is based on the detection and measurement of the light scattered from a pair of light

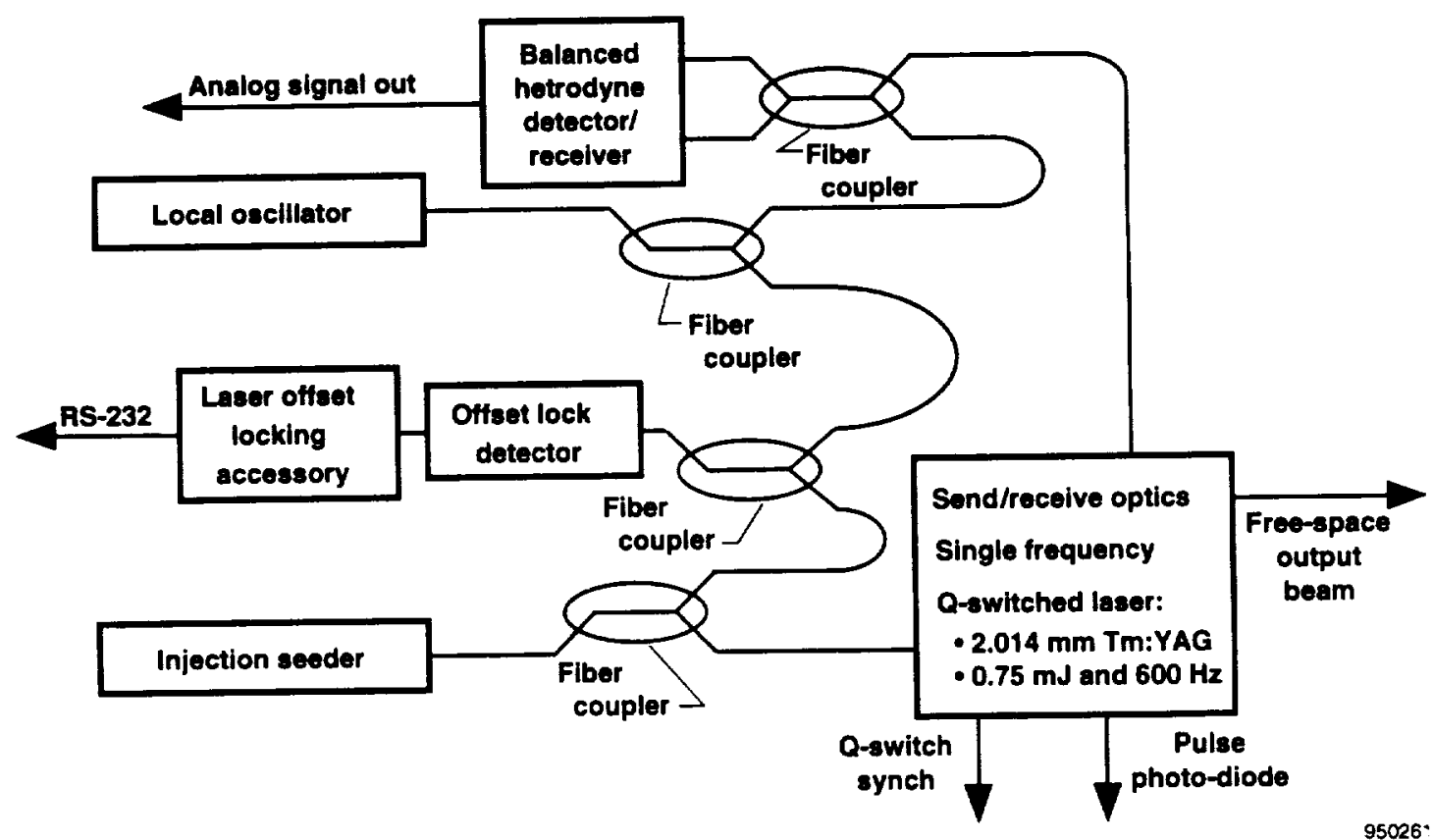

Figure 5. Diode-pumped, solid-state 2- $\mu \mathrm{m}$ Doppler lidar. 


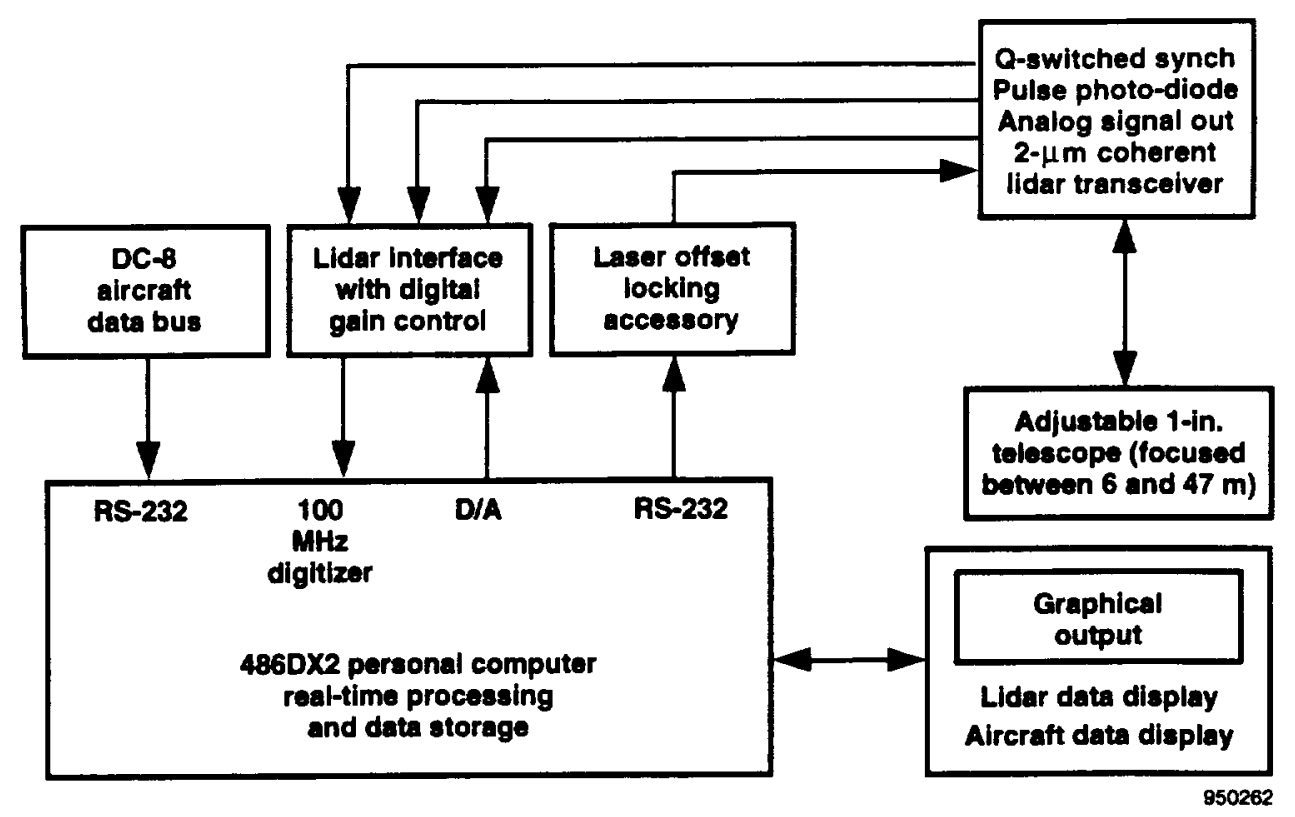

Figure 6. Flight-test hardware.

sheets by particulates naturally present in the Earth's atmosphere. These light sheets are projected from the vehicle. Time of flight of a particle between the sheets yields velocity. In addition, the received energy provides an estimate of its near-backscattering characteristics. Further details on the original sheet-pairs technology and its implementation in the flight instrument can be found in references [2], and [3].

The sheet-pairs system was designed and built between 1988 and 1990 . This system was subsequently test flown on an F-16B fighter aircraft in a program sponsored by the General Dynamics Corporation, Fort Worth, Texas. Then, the system was flown on F104 and SR-71 aircraft for NASA Dryden Flight Research Center, Edwards, California.

\section{Theory of Operation}

Light from two gallium aluminum arsenide, GaAlAs, lasers radiating at a wavelength of approximately $810 \mathrm{~nm}$ in the near infrared is projected from the vehicle to form an optical pattern. This pattern consists of two parallel sheets $100 \mu \mathrm{m}$ thick separated by an accurately calibrated distance. In the DC- 8 arrangement, these sheets were oriented perpendicularly to the predominant velocity direction and were spaced $11.55 \mathrm{~mm}$ apart. The optical throw was $1.220 \mathrm{~m}$.

As the sheet pair is swept through the atmosphere by the movement of the vehicle, the transit times of a sequence of particles during each update period are calculated. Airspeed may be computed from the known sheet-pair separation and the airborne laser transit anemometer (ALTA) installation geometry. Knowing the detector response and the characteristics of the signal processing subsystem, the energy received during a single sheet transit is derived.

If the backscattering properties of the particle are also known, or can be assumed, an optical radius (an equivalent spherical radius) can be estimated. This estimate of the optical radius is subject to ambiguity because scattering patterns are typically multivalued in the size regimes of interest here. In addition, the composition is unknown.

Figure 1 shows this behavior for a number of common atmospheric aerosol constituents. To simplify data analysis, an assumption consisting of a smoothed scattering characteristic obtained by performing a monotonic fit to the average curves for typical aerosols has been used in the interpretation of the DC- 8 results (fig. 7). 


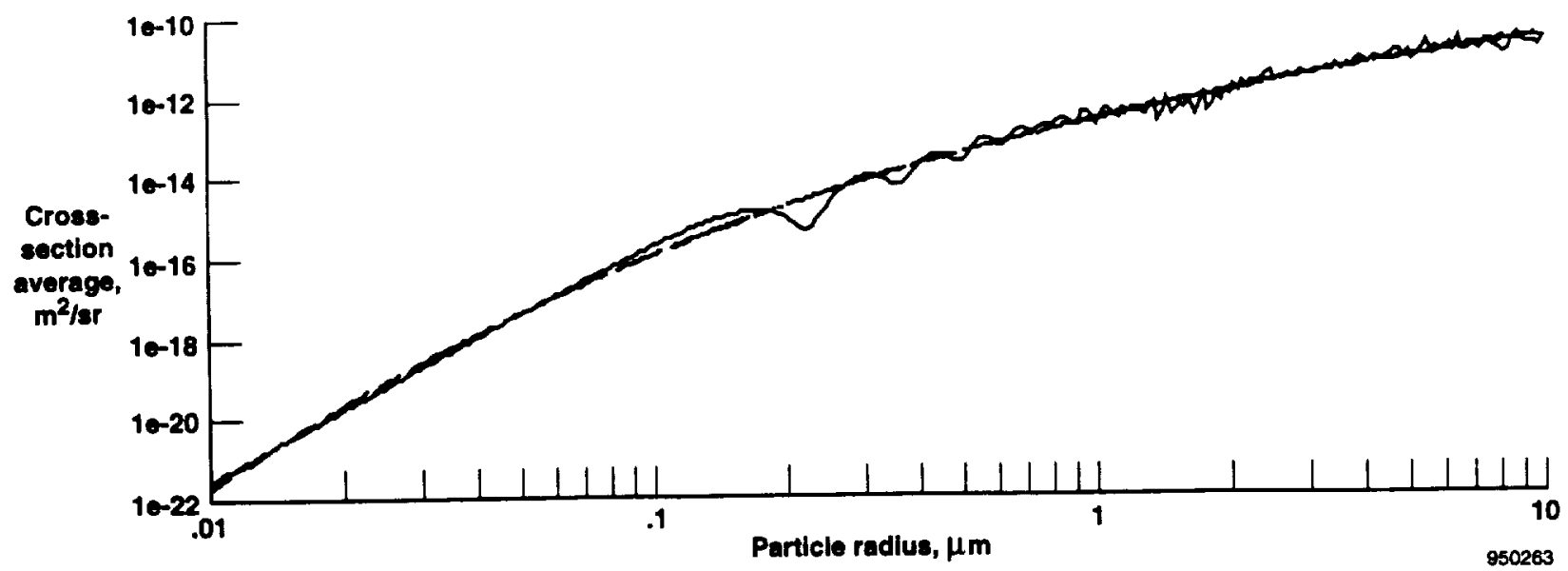

Figure 7. Analytic regression fits of radius to scattering cross-sections averaged over rural and maritime aerosols, sea salt, and sulfuric acid.

\section{System Description}

The sheet-pairs system was implemented as a set of enclosures, consisting of an optical head (ALTA), a power converter termed the auxiliary power supply equipment (APSE), a digital correlator and processor (DCAP), a remote chiller, and a personal computer. The ALTA unit houses the lasers, laser drivers, detectors, detector electronics, transmitter and receiver optics assemblies, and monitor electronics. The APSE included the power converters for the system and used the $110-\mathrm{V}$ aircraft supply as its power source. The DCAP unit houses the signal processing electronics and discriminator and correlator boards. The remote chiller provided liquid cooling for the lasers and avalanche photodiode detectors. This unit was needed because of the lack of a temperature-controlled air flow, such as had previously been used to cool the system. The personal computer was used to store the 1553 data stream produced by the sheet-pairs system. On previous programs, these data were downloaded through the aircraft 1553 bus onto a flight recorder, telemetered directly to a control room recorder, or both.

\section{CONTINUOUS WAVE DOPPLER LIDAR SYSTEM INSTALLATION AND PERFORMANCE}

One of the DC- 8 windows located $2 \mathrm{~m}$ forward of the wing at station 520 was replaced by an aluminum plate with a optical quality window installed in the center (fig. 2). This window was $75 \mathrm{~mm}$ in diameter, $3 \mathrm{~mm}$ thick, and coated to suppress reflections for $1.064 \mu \mathrm{m}$ at $30^{\circ}$. The $C D$ lidar brassboard was mounted to this plate with a mount that allowed the line-of-sight of the brassboard to be adjusted between $70^{\circ}$ and $90^{\circ}$ from the DC- $8 \times$-axis. For most of the flight, the angle was set to $75.6^{\circ}$. This configuration allowed observation of components of sideslip as well as forward velocity. It also eliminated the need to down-mix the signal to fit the bandwidth of the processor. Transmissive loss caused by changing the angle of the beam with respect to the window was on the order of 0.5 percent.

Because of the use of an efficient diode-pumped, solid-state laser, the heat generated by the CD brassboard and, thus, the energy requirements were minimal. As a result, no separate cooling of the lidar system was required. Once the brassboard was mounted, no further access to the lidar portion of the system was necessary.

The data processor and optional hardware used to store raw data were mounted in a short rack provided by NASA at station 560 . The return signal from the lidar was periodically monitored throughout the series of flight tests to take raw data sets to augment the continuous time and velocity data provided by the burst processor. 


\section{Preflight Testing}

All preflight testing and alignment procedures were performed in the laboratory at Boeing Defense \& Space Group, Seattle, Washington. The system was aligned interferometrically such that the local oscillator and return signal were coplanar, and the detector was then aligned to the combined beams.

Next, the brassboard system alignment was completed and the system was flown from Seattle to Moffett Field and then installed onto the DC-8 airplane. No attempts were made to modify the alignment after that point. A check of the alignment, after the brassboard was removed from the DC-8 and returned to Seattle, showed that the fringe pattern, and therefore the interferometric alignment, had not changed over the course of $23 \mathrm{hr}$ of DC-8 flight tests. Nor had changes occurred because of the handling required to transport the system back and forth to Moffett Field, California.

\section{Airspeed and Sideslip Measurements}

Data taken by the system during the four DC-8 flight tests were compared with the corresponding data from the pitot-static based airdata system onboard the aircraft. Table 4 summarizes the salient features of these flights. Balloons on altitude time history graphs refer to specific data segments.
Figure 8 is an overlay of the CD lidar data with TAS from the DC- 8 data distribution subsystem (DADS). This graph shows a 10-min run of data taken in a range of relatively clear conditions. No haze or water and ice crystal clouds were visible. The data for this graph were taken with the DC-8 in a uniform descent from $35 \mathrm{kft}$ down to $5 \mathrm{kft}$. (See reference CD1 segment for the fourth flight, table 4.) These data represent results from a single run. This run was selected because the conditions were among the clearest encountered during the four flights and covered a wide range of altitudes. To compensate for the nearside-looking geometry, the measured line-of-sight velocities have been divided by $\cos 75.6^{\circ}$ before plotting.

Several points along the graph appear to be substantially out of line with the rest of the data ( $~ 12$ outliers among 2500 detections during the 10-min data run). These points are probably false alarms which were erroneously validated by the signal processor. Because the processor does not save any record of point-by-point spectral profiles or signal strengths, reviewing its validation process is impossible. Variations in the EML detection rate are obvious in the clumping of detections displayed as a function of time. The observed data rate varied between roughly 1 and $300 \mathrm{~Hz}$ during this particular run.

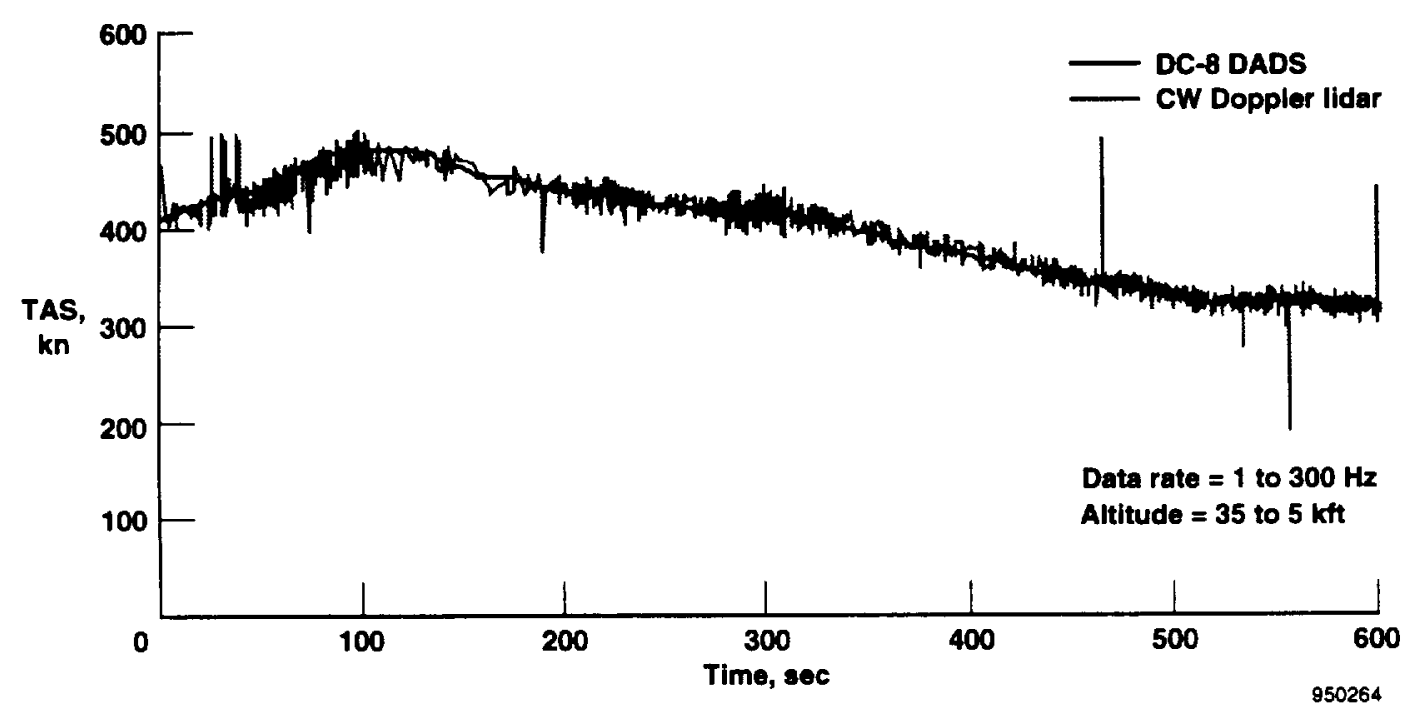

Figure 8. Overlay of the continuous wave Doppler system and DC-8 DADS true airspeed data. 
Table 4. Flight Summary

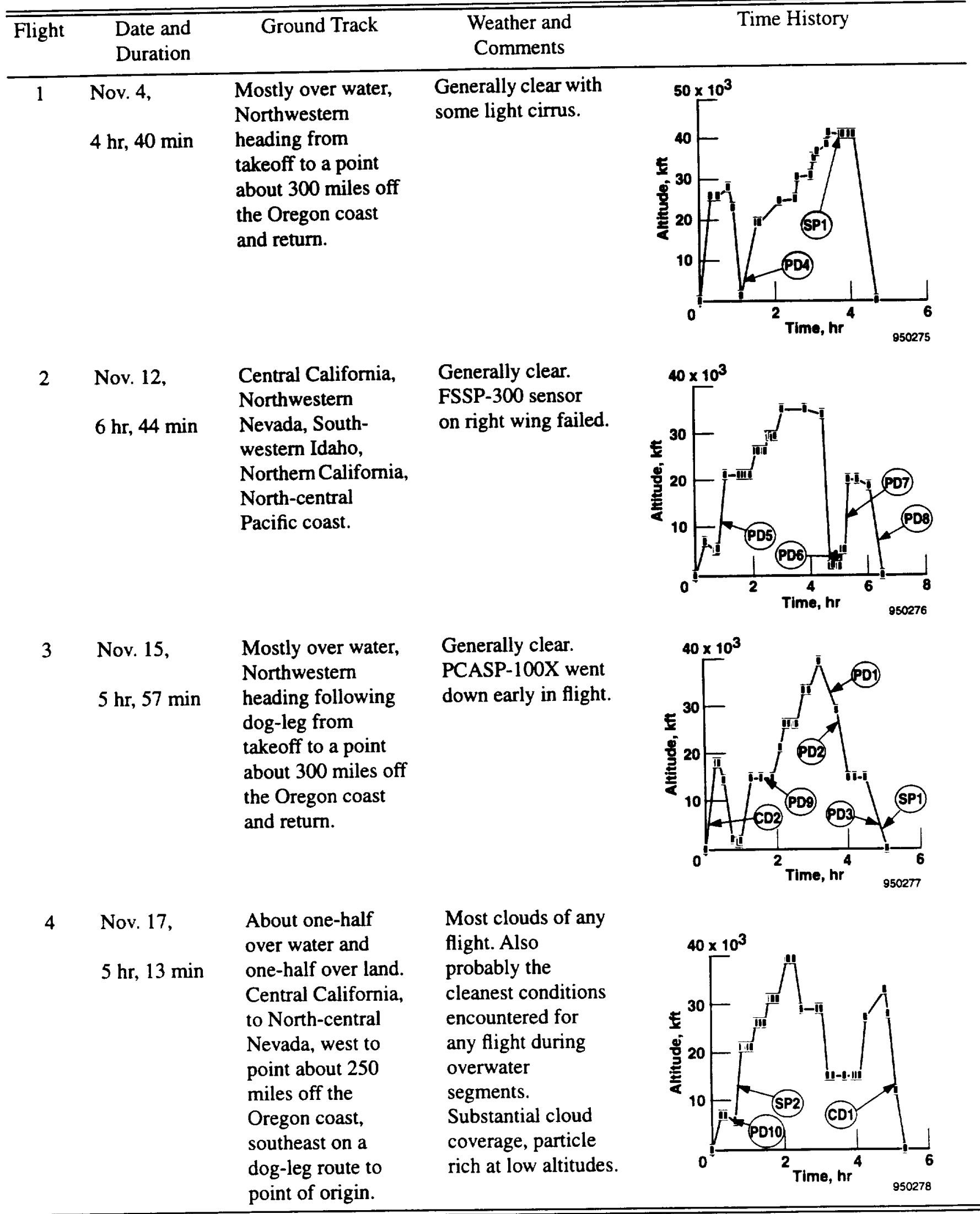


Note that part of the variation between the DADS and the $C D$ lidar measurement is attributable to turbulence. When performing the coordinate transformation to provide TAS for the $75.6^{\circ}$ viewing angle, the turbulence contribution is scaled at the same ratio as the steady-state factor (in this case $1 / \cos 75.6^{\circ}$ or 4.02 ). This process overemphasizes the difference attributable to turbulence between the DADS airspeed data and the CD lidar data, so the agreement is, in fact, substantially better than the figures suggest. This process applies only to the random difference and does not affect any steady-state variations between the $C D$ lidar measurement and the DADS measurement.

Figures 9,10 , and 11 show representative samples of the conditions encountered over four flights. Figure 9 shows a 5-min run of data taken in relatively clear conditions. No haze or water and ice crystal clouds were visible. The DC- 8 was in a shallow uniform ascent starting at $5 \mathrm{kft}$. (reference CD2 segment on third flight, table 4.) The observed data rate during this run was nominally $7 \mathrm{~Hz}$, and the focal distance for the system was $1 \mathrm{~m}$.

Because the beam line-of-sight geometry is not aligned in parallel with either the forward or the transverse velocity vectors of the aircraft, the measurement represents a combination of these velocities. These vectors are shown in figure 2 as $x$ and $y$. With the near-side-looking geometry, the contribution to the line-of-sight velocity from the forward velocity component is small (scaled by cos $75.6^{\circ}$ ) compared to the contribution from the transverse velocity component (scaled by $\sin 75.6^{\circ}$ ). This configuration can be viewed as mostly observing a component of the sideslip of the airplane combined with the forward velocity.

At first glance, figure 9 appears to indicate a poor correlation between the DADS TAS and the CD-measured TAS. Closer evaluation of the DC-8 wind speed and direction measurements reveals a fairly strong wind shift or shear contribution to the measured line-of-sight velocity. The measured speed of the wind averages approximately $15 \mathrm{kn}$ and shifts first as much as $50^{\circ}$ to the starboard side of the aircraft (at $100 \mathrm{sec}$ ) and then shifts $50^{\circ}$ to port (at $125 \mathrm{sec}$ ). The deep well at $125 \mathrm{sec}$ represents an angle of sideslip of approximately seven-tenths of $1^{\circ}$ which is a good indicator of the sensitivity of the EML velocity measurements.

\section{Data Rate Versus Altitude}

Figure 10 shows the data rate as a function of altitude. The data rate (detections/sec) is updated every $10 \mathrm{sec}$. This rate includes information from the entire four-flight sequence except for in-cloud conditions where data rates were very high and includes over 10,000 data points. Data rates on the order of $10 / \mathrm{sec}$ prevail over the $5-\mathrm{k}$ to $40-\mathrm{kft}$ altitude range. The lowest detection rates observed during this run

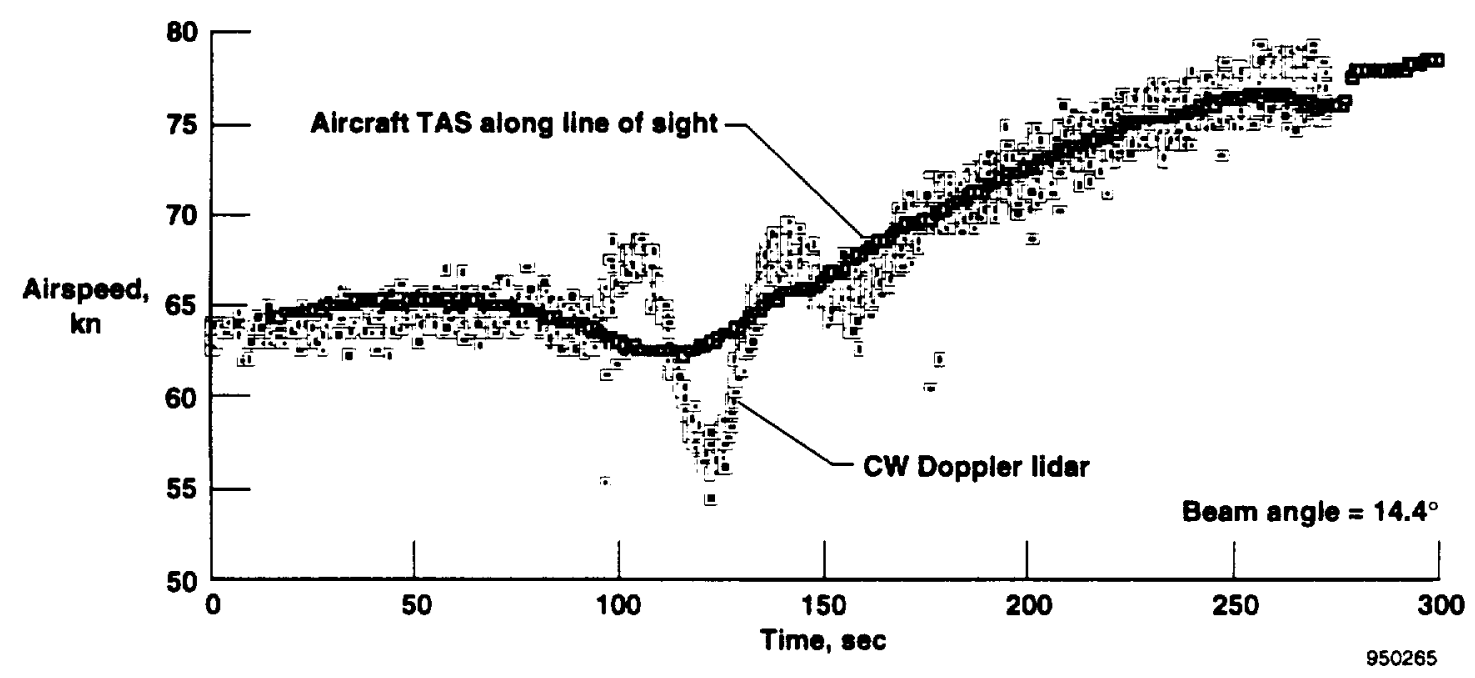

Figure 9. Overlay of the continuous wave Doppler and DADS TAS with a sideslip component. 


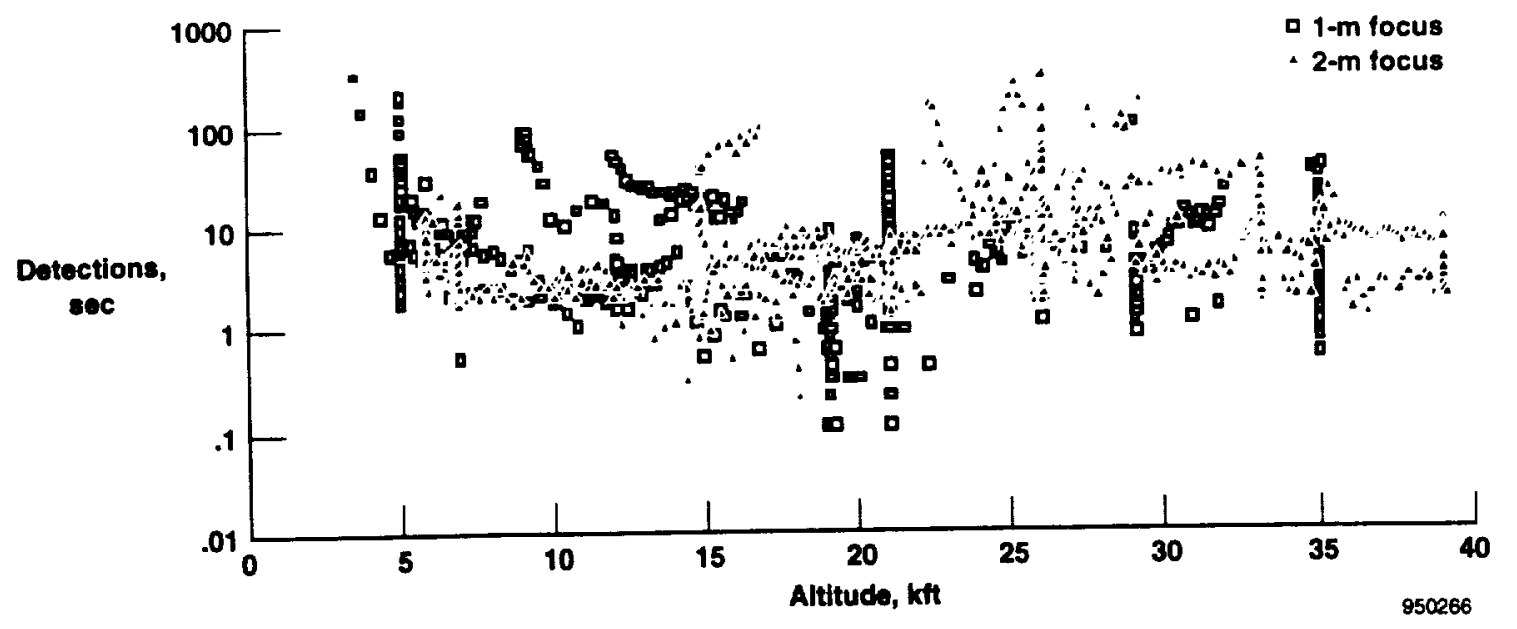

Figure 10. The CD lidar data rate as a function of altitude.

occurred at 20 to $25 \mathrm{kft}$. At this altitude range, minimum aerosol number densities were expected.

These data clearly reveal that it is very difficult to find correlations between detection rate and altitude. The cleanest air that was encountered on any of the previous flight tests at altitudes up to $18 \mathrm{kft}$ was at approximately $6 \mathrm{kft}$. This air was encountered close to the Cascade Mountains in Washington where the air had apparently been effectively scrubbed of particles by a passing cloud front [4]. Direct comparisons are difficult because the laser systems differed between this test and previous tests. However, the aerosol density minimum on the DC- 8 test series is thought to be lower than any encountered on previous tests.

\section{Turbulence and Error Analysis}

To analyze the error associated with the CD system, separating the data variation caused by atmospheric turbulence from that resulting from system measurement uncertainty was necessary. Although not exhaustive, this analysis provides an estimate of the system measurement uncertainty.

Gaining a full understanding of the effects of turbulence requires a fairly complete error analysis of the flight-test data. This analysis would need to include a power spectral density (PSD) calculation of a large statistical sample of the data. Because of limited resources, this effort focused on the standard deviation of the TAS at high detection rates $(>1.5 \mathrm{kHz})$ to minimize the effects of turbulence.
Figure 11 shows a histogram of the line-of-sight velocity component data along with the number of detections in each bin. These data were taken in haze at a constant velocity. The measured standard deviation is $0.84 \mathrm{kn}$ and corresponds to the repeatability of the CD system TAS measurement. Data from the University of Washington flight tests were taken at $>30 \mathrm{kHz}$ in clouds with a separation between data points of $\sim 0.5 \mathrm{~cm}$. These data showed an observed standard deviation of $0.33 \mathrm{kn}$. Even with the factor of 2 or 3 increase from the previous University of Washington tests, noise and turbulence effects resulted in an uncertainty less than $1 \mathrm{kn}$.

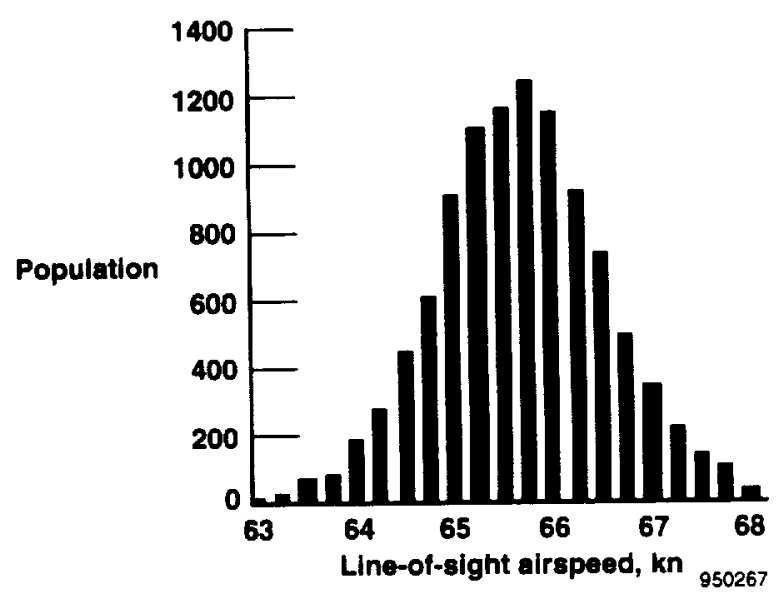

Figure 11. Histogram of $\mathrm{CD}$ error bandwidth. 
Problems and Lessons Learned with the Continuous Wave Doppler Lidar System

With automated computer-based acquisition systems, a temptation to acquire very large data sets exists. In this experiment, it was learned that reducing the data sets to manageable size by deleting and editing consumed substantial time. In addition, special processing programs were needed to perform this task.

On the first flight, the 75-mm window completely fogged over because of the difference between the outside air and the cabin temperature. The system continued to make detections at a decreased rate before the discovery was made that the entire window had fogged over. On subsequent flights, a dry nitrogen flow was used to keep the window clear.

\section{PULSED DOPPLER LIDAR SYSTEM INSTALLATION AND PERFORMANCE}

An uncoated, fused silica window was installed in the DC-8 window position located on the left side just forward of the wing at station $\mathbf{5 9 0}$ for use as the system optical port (fig. 2). The pulsed Doppler lidar transceiver head was mounted on a fixture attached to the aircraft immediately behind the power supply and control rack. A second rack contained the control system and data acquisition processor used to process and store raw data. The transceiver was positioned at an angle of $45^{\circ}$ with the window surface. This configuration minimized the reflection losses through the window while at the same time afforded a more nearly forward-looking beam direction. The true hetrodyne nature of the system resulted in a smaller Doppler signal frequency that was adjusted periodically to keep the frequency within range of the detector. This offset capability allowed the system to accommodate the large Doppler frequency that results from a directly forward-looking configuration at the $2-\mu \mathrm{m}$ wavelength $(0.5 \mathrm{MHz} / \mathrm{kn})$.

\section{Pre/Postflight Testing}

Before and between flight tests the 2- $\mu \mathrm{m}$ lidar was calibrated to determine its overall heterodyne efficiency. This calibration was necessary to accurately relate the backscattering coefficient measured with the $2-\mu \mathrm{m}$ lidar to that obtained from the PMS. A calibrated Lambertian scatterer was used to determine the overall heterodyne efficiency of the $2-\mu \mathrm{m}$ lidar.

The procedure used to calibrate the $2-\mu \mathrm{m}$ lidar is consistent with that used to successfully calibrate a 1.06- $\mu \mathrm{m}$ lidar [10]. The detection bandwidth for the calibration was $0.7 \mathrm{MHz}$, which is consistent with the Gaussian laser pulse length of $0.75 \mu \mathrm{sec}$. For a $2-\mu \mathrm{m}$ lidar, this bandwidth corresponds to a noise equivalent power (NEP) of $6.9 \times 10^{-14} \mathrm{~W}$. The $2-\mu \mathrm{m}$ lidar emitted approximately $750 \mu \mathrm{J} /$ pulse which corresponds to a peak power of $1 \mathrm{~kW}$. The waist diameter of the exit beam was $12.7 \mathrm{~mm}$. The beam was transmitted at a $45^{\circ}$ angle to the uncoated fused silica window and focused at a distance of $47 \mathrm{~m}$ onto the target.

Because the target was a Lambertian scatterer, the return signal power within the acceptance angle of the detector and with the proper polarization was $4.6 \mu \mathrm{W}$. With an NEP of $6.9 \times 10^{-14} \mathrm{~W}$, the SNR for this measurement should be $78 \mathrm{~dB}$. The measured value was $58 \mathrm{~dB}$, indicating that the system was operating $20 \mathrm{~dB}$ below the quantum noise limit. Because each surface of the fused silica window reflected approximately 7.7 percent of the circularly polarized light, only 73 percent reached the receiver. Thus, the window accounted for nearly $1 \mathrm{~dB}$ of the loss.

Because the photon noise was $10 \mathrm{~dB}$ above the detector and preamp noise, it was determined that the fiber couplers were responsible for the remaining loss in the system. Unfortunately, the fiber couplers could not be replaced before or between the flight tests. No changes in the heterodyne efficiency were observed during the four flight tests.

\section{True Airspeed Correlation}

The aircraft airspeed derived from the DADS onboard the DC-8 was monitored in real time such that the LOLA could be adjusted to cancel the majority of the platform velocity. In the future, the most recent Doppler IF signal would be used to set the LOLA; however, using the DADS airspeed was the most straight forward method for these flight tests. Use of the LOLA to cancel the platform velocity allows for maintenance of the Doppler IF near $20 \mathrm{MHz}$. This frequency is within the bandwidth capability of the $100-\mathrm{MHz}$ sample rate analog-todigital conversion board. 
To monitor lidar performance during these flight tests, the estimated lidar aerosol velocity was displayed in real time on the computer monitor. This display resulted from performing fast Fourier transforms (FFT) on selected shots, recognizing the spectral peak, and displaying the lidar TAS estimate with data gathered using DADS.

The lidar and DADS TAS estimates are compared for three time intervals in figures 12 (a)-12(c). These data sets represent $13 \mathrm{~min}$ of over $10 \mathrm{hr}$ of flight-test data recorded during the four flights. However, they do show the excellent agreement found between the two methods of measuring TAS. Note that part of the variation between the DC- 8 airplane and the PD lidar measurement is attributable to turbulence. When performing the coordinate transformation to provide TAS from the $45^{\circ}$ viewing angle, the turbulence contribution is scaled at the same ratio as the steady-state factor (in this case by $1 / \cos 45^{\circ}$ or 1.41 ). This process over-emphasizes the difference between the DC- 8 airspeed data and the lidar data, so the agreement is, in fact, better than figures 12(a)-12(c) suggest.

The flight-test data shown in figure 12 were acquired during flight 4 on November 17, 1993. The data set in figure 12(a) was acquired between $31 \mathrm{kft}$ and $33.5 \mathrm{kft}$, (reference PD1 segment on fourth flight, table 4). Figure 12(b) was acquired at $26 \mathrm{kft}$, (reference PD2 segment on fourth flight, table 4) Figure 12(c) was acquired between $7 \mathrm{kft}$ and $500 \mathrm{ft}$ just before landing (reference PD3 segment on fourth flight, table 4). These curves confirm that the use of Doppler lidar to sense an off-axis TAS component with transformation to flightpath TAS [11] is an effective comparison technique for verifying the performance of an airborne pulse Doppler lidar system.

\section{Backscatter Coefficient and Signal-to-Noise Ratio}

Figures 13 and 14 show characteristic lidar SNR data. Both figures show the logarithmic distribution of SNR for two 2-min periods. Figure 13 shows data obtained at an altitude of $1.8 \mathrm{~km}(5.9 \mathrm{kft})$ (reference PD10, flight 4, table 4) with the lidar beam focused at a distance of $47 \mathrm{~m}$. Measurement volume was $4400 \mathrm{~cm}^{3}$. The TAS was $140 \mathrm{~m} / \mathrm{sec}(272 \mathrm{kn})$, so these data were taken over a flightpath of nearly $17 \mathrm{~km}$. The peak is found centered at $13 \mathrm{~dB}$ with $1 / \mathrm{e}^{2}$ tails at 9 and $17 \mathrm{~dB}$.

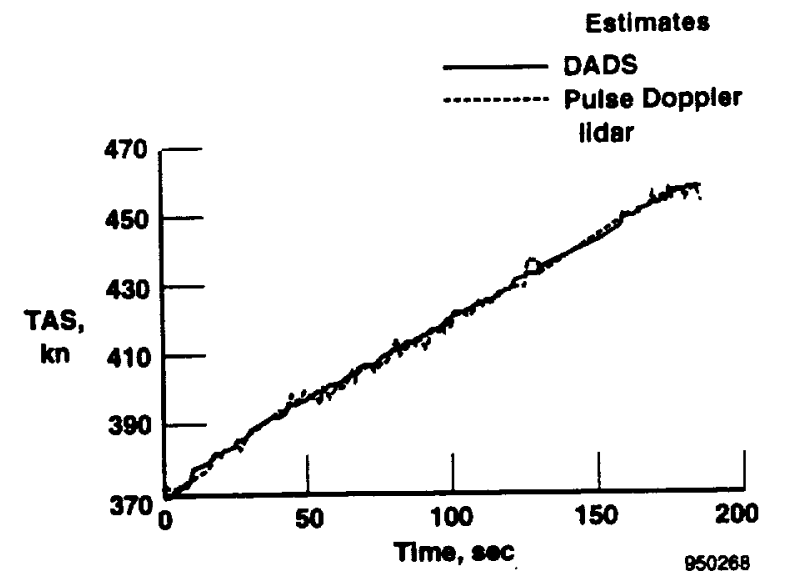

a. The PD lidar and DADS TAS comparison at 31 to $33.5 \mathrm{kft}$ altitude.

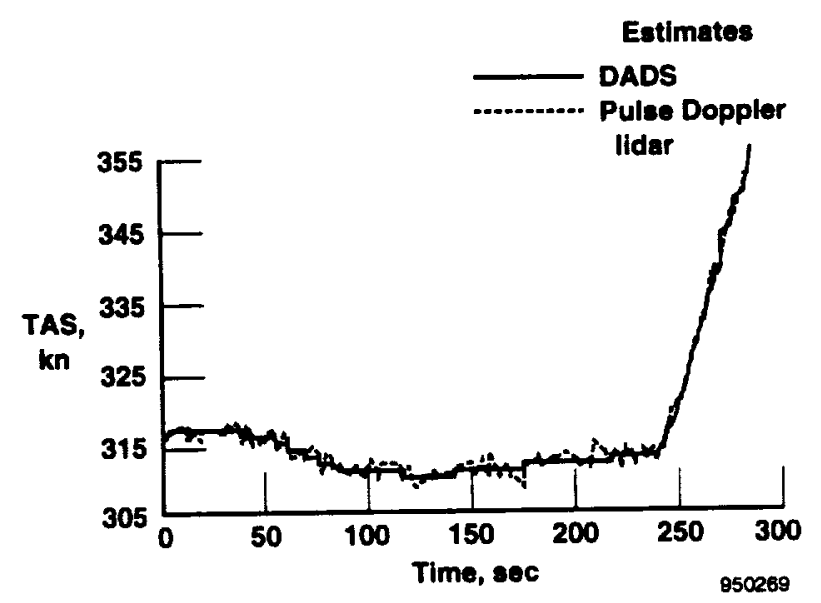

b. The PD lidar and DADS TAS comparison at $26 \mathrm{kft}$ altitude.

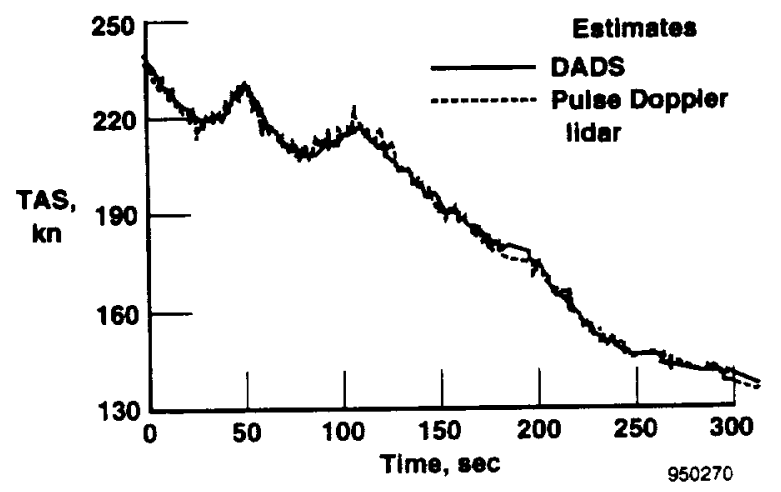

c. The PD lidar and DADS TAS comparison at $7 \mathrm{kft}$ to $500 \mathrm{ft}$.

Figure 12. Three curves representing over $13 \mathrm{~min}$ of flight test results. 
Figure 14 shows flight-test data acquired at an altitude of $7.9 \mathrm{~km}(25.9 \mathrm{kft})$ and with the lidar beam focused at a distance of $20 \mathrm{~m}$. Measurement volume was $144 \mathrm{~cm}^{3}$. The TAS was $160 \mathrm{~m} / \mathrm{sec}$, so these data were taken over a flightpath in excess of $19 \mathrm{~km}$. The peak is found centered at $22 \mathrm{~dB}$ with $1 / \mathrm{e}^{2}$ tails at 14 and $30 \mathrm{~dB}$.

The two logarithmic distributions presented in figures 13 and 14 represent the large data set acquired during these four flight tests. In general, no significant SNR fluctuations were observed from pulse to pulse $(1.67 \mathrm{msec})$. This result is probably not surprising because the aircraft moves a fraction of a meter during the $1.67-\mathrm{msec}$ period. The measurement volume length was generally several meters. However over the

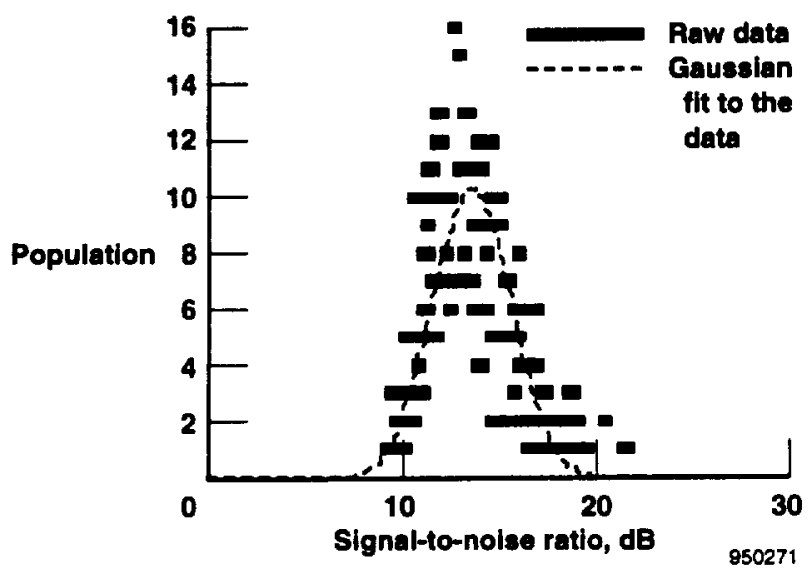

Figure 13. The PD lidar SNR data at $47 \mathrm{~m}$.

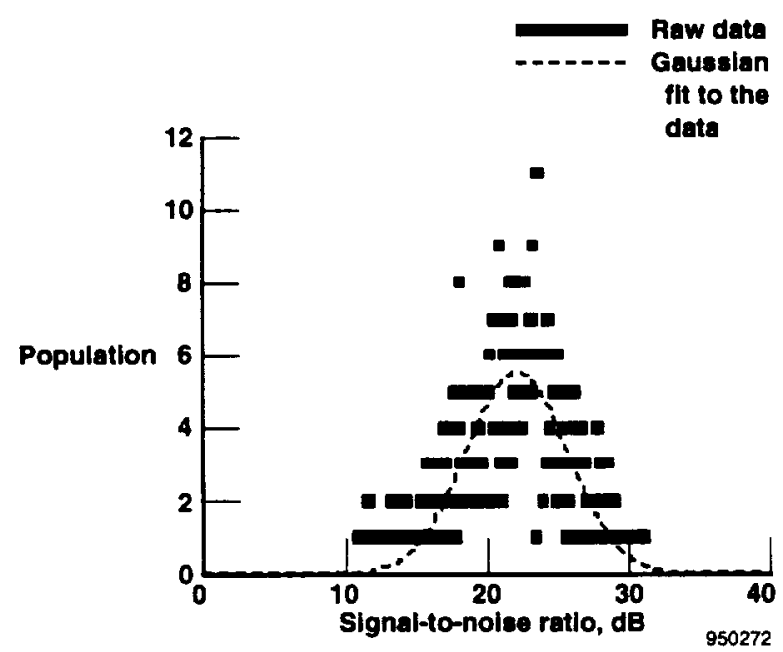

Figure 14. The PD lidar SNR data at $20 \mathrm{~m}$. course of seconds, the aircraft does travel several hundred meters. It is on this time frame that the logarithmic distribution is observed.

This spatial logarithmic distribution is similar to the temporal logarithmic distribution reported by Madison J. Post [12]. Reference 15 shows a logarithmic distribution of $\beta_{\pi}$ over a 3-month period at an altitude of $13 \mathrm{~km}(42.6 \mathrm{kft})$. Post showed that $\beta_{\pi}$ varied by approximately $15 \mathrm{~dB}$ over that period. Thus, system engineers and lidar applications planners should expect signal-to-noise variations spanning $15 \mathrm{~dB}$ or more for focused Doppler lidar systems.

\section{Determination of 2- $\mu \mathrm{m}$ Lidar Backscatter Coefficient}

The lidar $\beta_{\pi}$ estimate was determined from the SNR of the $2-\mu \mathrm{m}$ lidar flight-test data. The SNR for a coherent focused heterodyne system obtaining a return from a diffuse scattering medium is given by equation 5 and found in reference 13 as follows:

$$
\mathrm{SNR}=\frac{2 \eta \mathrm{P}_{0} \beta_{\pi} \lambda^{2}}{h c B}
$$

where $\eta$ is quantum efficiency of the heterodyne system (detector and optics - determined to be 0.01 above), $P_{0}$ is the laser peak power ( $\left.1 \mathrm{~kW}\right), \beta_{\pi}$ is the backscatter coefficient $\left(\mathrm{m}^{-1} \mathrm{sr}^{-1}\right), \lambda$ is the wavelength $(2.01 \mu \mathrm{m}), h$ is Planck's constant $\left(6.626 \times 10^{-34}\right.$ $\mathrm{J}-\mathrm{sec}), c$ is the velocity of light $\left(2.998 \times 10^{8} \mathrm{~m} / \mathrm{sec}\right)$, and $B$ is the bandwidth determined by the pulse length $(0.7 \mathrm{MHz})$. Equation 5 can be solved for $\beta_{\pi}$ to yield

$$
\beta_{\pi}=\frac{(\mathrm{SNR}) h c B}{2 \eta \mathrm{P}_{\mathrm{o}} \lambda^{2}}
$$

Equation 6 indicates that $\beta_{\pi}$ is directly proportional to SNR. The minimum detectable backscatter coefficient, $\beta_{\pi_{\min }}$, is defined as the value of $\beta_{\pi}$ when the lidar signal equals the shot noise limited floor of the lidar heterodyne detector. That is, SNR $=1$. Thus, the lidar $\beta_{\pi}$ estimate equals the SNR multiplied by $\beta_{\pi_{\min }}$. Using equation 6 and parameters defined here, it was determined that the $2-\mu \mathrm{m}$ lidar used during these flight tests had a $\beta_{\pi_{\min }}=1.7 \times 10^{-9}\left(\mathrm{~m}^{-1} \mathrm{sr}^{-1}\right)$. 


\section{Particle Measurement System Comparison}

The lidar and PMS-derived $\beta_{\pi}$ were calculated for seven intervals as summarized in table 5 [14]. The date, time, altitude range, and measurement volume are shown for each time interval. The fifth column shows the average $\beta_{\pi}$ estimate determined from the PMS during the interval of interest.

The sixth column in table 5 shows the average lidar $\beta_{\pi}$ value observed over the stated interval. Because lidar data tend to have significant variations (figs. 13 and 14), the logarithmic average value of $\beta_{\pi}$ was used as the lidar $\beta_{\pi}$ estimate. For data with a large dynamic range, the logarithmic average will be smaller than an arithmetic average and will, in fact, contribute to the spread in the PMS and lidar ratio.

The seventh column shows the ratio of the PMS $\beta_{\pi}$ to the lidar $\beta_{\pi}$. During one of the time periods shown in table 5 , the $\beta_{\pi}$ was too low to obtain a lidar $\beta_{\pi}$ estimate. Indeed, at this same point in the flight, the PMS $\beta_{\pi}$ estimate was at the minimum detectable lidar $\beta_{\pi}$ as determined from our lidar calibration. Note that this was the lowest PMS $\beta_{\pi}$ observed during the four flight tests.

In general, a good relative correlation was found between the PMS and lidar $\beta_{\pi}$ estimates, but the lidar $\beta_{\pi}$ was approximately $5 \mathrm{~dB}$ less than that estimated by the PMS. This value is consistent with that observed for a similar comparison at $1.06 \mu \mathrm{m}$ [10]. A portion of this difference can be attributed to interference effects in the coherent measurement. Errors in calibrating the PMS and lidar systems and analysis assumptions may also play a role.

\section{Problems and Lessons Learned with the Pulsed Doppler Lidar System}

The 2- $\mu \mathrm{m}$ Doppler lidar was rugged and showed no significant deterioration within the airborne environment. Results show excellent agreement between the Doppler lidar and DADS TAS estimates. Reasonable correlation existed between the $\beta_{\pi}$ as obtained from the Doppler lidar and PMS.

Table 5. Comparison of PMS and lidar $\beta_{\pi}$ estimates for seven intervals.

\begin{tabular}{|c|c|c|c|c|c|c|}
\hline $\begin{array}{c}\text { Ref. date, } \\
1993\end{array}$ & Time, UT & $\begin{array}{c}\text { Altitude, } \\
\text { kft }\end{array}$ & $\begin{array}{c}\text { Measured } \\
\text { Volume, } \\
\mathrm{cm}^{3}\end{array}$ & $\begin{array}{l}\text { PMS } 2-\mu \mathrm{m} \\
\beta_{\pi}, \mathrm{m}^{-1} \mathrm{sr}^{-1}\end{array}$ & $\begin{array}{c}\text { Lidar } \beta_{\pi} \\
\mathrm{m}^{-1} \mathrm{sr}^{-1}\end{array}$ & $\begin{array}{l}\beta_{\pi} \text { ratios, } \\
\text { PMS/Lidar }\end{array}$ \\
\hline $\begin{array}{c}\text { Nov. } 4 \\
\text { PD4 }\end{array}$ & $21: 06-21: 10$ & $1.0-2.5$ & 1.22 & $9.8 \times 10^{-8}$ & $2.1 \times 10^{-8}$ & 4.6 \\
\hline $\begin{array}{c}\text { Nov. } 12 \\
\text { PD5 }\end{array}$ & $18: 40-18: 49$ & $6.7-16.0$ & 144 & $3.3 \times 10^{-8}$ & $1.7 \times 10^{-8}$ & 1.9 \\
\hline PD6 & $22: 54-22: 58$ & $1.8-5.1$ & 1.22 & $9.4 \times 10^{-8}$ & $2.6 \times 10^{-8}$ & 3.6 \\
\hline PD7 & $23: 04-23: 10$ & $5.8-19.2$ & 1.22 & $1.7 \times 10^{-9}$ & N/A & N/A \\
\hline PD8 & $00: 01-00: 09$ & $12.1-1.5$ & 1.22 & $9.3 \times 10^{-8}$ & $2.8 \times 10^{-8}$ & 3.3 \\
\hline $\begin{array}{c}\text { Nov. } 15 \\
\text { PD9 }\end{array}$ & $21: 52-21: 55$ & 14.9 & 144 & $6.7 \times 10^{-8}$ & $2.5 \times 10^{-8}$ & 2.7 \\
\hline $\begin{array}{c}\text { Nov. } 17 \\
\text { PD10 }\end{array}$ & $18: 42-18: 43$ & 5.9 & 4425 & $1.5 \times 10^{-7}$ & $3.8 \times 10^{-8}$ & 3.9 \\
\hline
\end{tabular}


Two problems were identified with the $2-\mu \mathrm{m}$ lidar system. One was the excessive losses in the interferometer. Although this problem limited lidar performance during these flight tests, building an efficient interferometer is certainly not a new science and thus can and will be corrected for future demonstrations.

The second problem involved vibration affects on the master oscillator to seed laser frequency-locking process. The $2-\mu \mathrm{m}$ lidar used the well-known pulse build-up time-locking technique. The kilohertz vibration environment during airbome operation interfered with the locking process because the bandwidth of the locking circuit is limited to a few hundred hertz. The locking circuit bandwidth was sufficient for the $600-\mathrm{Hz}$ pulse repetition frequency but was inadequate for the airborne vibration environment. As a result, the frequency of the outgoing pulses was randomly locked to the seed laser frequency. Luckily, a very good relationship exists between offset frequency and pulse build-up time. As a result, pulse build-up time was used to determine which of the outgoing pulses were "good", that is, coincided with the seed laser frequency.

Three main lessons were learned during these flight tests. First, the pulse build-up time-locking technique is not sufficient in the airborne environment for low pulse repetition frequency lasers $(600 \mathrm{~Hz}$ or lower). A ramp and locking technique is more appropriate for the airborne environment and has recently been implemented by Lightwave Electronics, Mountain View, California, and tested in the laboratory environment. The second lesson is that the lidar and PMS $\beta_{\pi}$ estimates correlated very well. Thirdly, the laser power levels demonstrated during this flight test should be sufficient for airdata operation over altitudes up to $85 \mathrm{kft}$ based on aerosol concentration measurements.

\section{SHEET-PAIRS TIME-OF-FLIGHT SYSTEM INSTALLATION AND PERFORMANCE}

Except for the chiller and the optical head, ALTA, the sheet-pairs system, was installed on the DC- 8 airborne laboratory between stations 480 and 500 on a short rack provided by NASA (fig. 2). The installation was completed in such a way that the computer could be accessed easily from seats mounted just behind station 520. The ALTA was installed on a rack which was mounted to the wall of the aircraft between stations 440 and 460 . This installation positioned the ALTA optical axis nearly normal to the airflow and pointing $8.2^{\circ}$ upward in level flight. The chiller was mounted in the cargo bay under the optical head. Fluid lines were routed up to the optical head directly through the flooring. The chiller was equipped with a main power switch which was independent of the rest of the system. The aircraft parameter data available from the DC-8 DADS were downloaded from the NASA archive at the postflight processing stage and incorporated in the flight data set with the appropriate timing information.

\section{Preflight Testing}

To achieve precise alignment of the images of the sheet pairs, a scattering surface was positioned in the sheet focal region. The sheets become clearly visible with the aid of an infrared viewer. An air-jet consisting of two industrial blowers, a stilling chamber, and a stainless steel nozzle was used to test the functionality of the system. The air-jet was also used to perform preliminary checks on software algorithm and electronic circuitry modifications. This arrangement produced an airflow with a maximum speed of about $120 \mathrm{~m} / \mathrm{sec}(233 \mathrm{kn})$.

\section{Airspeed}

Many plots of the measured velocity component were generated from the raw data in the flight records. Each segment lasted from 2 to $5 \mathrm{~min}$. Where particle populations were virtually continuous, agreement between the measurements and the airspeed data available from the DADS was generally very good.

Figure 15 shows one direct TAS comparison between the sheet-pairs data and the DC-8 DADS for a continuous 18 -min sequence on flight 3 . Pressure altitude during this sequence ranged from $5 \mathrm{kft}$ at the beginning of the run to slightly over $1 \mathrm{kft}$ at the conclusion. The DC-8 airspeed measurement was derived from pressure ports located in the nose region of the fuselage and the sheet-pairs measurement was located off the surface near station 520 along the side of the fuselage (fig. 2). The offset between the two measurements probably results from local speed and flow angularity differences between the two locations. 


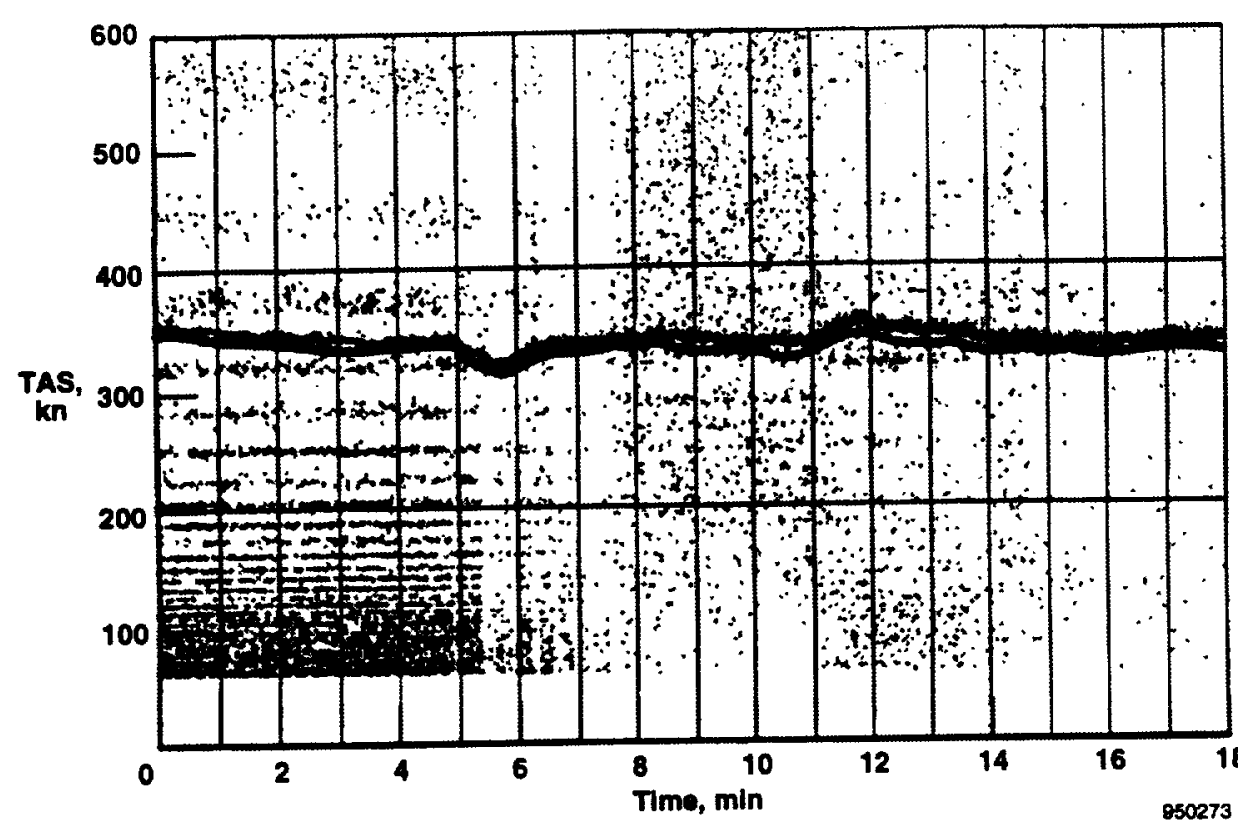

DC-8 onboard system OADS airspeed data

Figure 15. Comparison of sheet-pairs TAS and DC-8 DADS airspeed measurements.

Data in figure 15 represent comparison quality ranging from marginal to very good in terms of data outliers. These data show two types of outliers. The random distribution arises when the aerosol detection or sheet-pair particle delay times are invalid (center and right). The false banding may be caused by an erroneous integer rollover or sizing misclassifications in the processing algorithm (left).

\section{Sheet-Pairs Particle Characteristics and Particle Measurement System Comparison}

Figure 16 shows particle concentration distribution derived from a segment of the sheet-pairs data obtained during the flight of November 17, 1993 (reference SP1 segment on flight 3, table 4). The solid lines represent the PMS measurement values from the FSSP-300 probe on the left wingtip. The dashed lines are from a similar probe on the right wingtip. Note that no information was obtained from the right probe for the 2.0 to 4.0 radius range.

A preliminary comparison with particle concentration results reveals that in some size regions the sheetpairs distribution data slopes are similar to those from the FSSP-300 data. On the other hand, absolute concentration values match closely in only one size bin and may be as much as $2-1 / 2$ orders of magnitude lower in the case of the sheet-pairs system measurements. The explanation is probably found in the variable sheet-pairs particle time sampling window.

\section{Results Assessment}

A full analysis of errors is beyond the scope of this report. References 2 and 3 contain detailed information regarding sources of instrumental error. However, some general comments on the results from the DC- 8 flights should be made.

An inherent source of error in the system is noise generated by ambient or background illumination. The most intense source during daylight hours is, of course, the sun. As a consequence, the smallest detectable scattered light signal is a strong function of the angle between the optical axis and the direct line to the sun. On some occasions, velocity measurements with the sheet-pairs system were impossible when this angle was less than about $30^{\circ}$.

Remember that particle sizes were estimates obtained based on the assumption of a particle with generic scattering properties. Such particle sizes can be expected to indicate aerosol characteristics only in some average manner. For this reason, no error bars have been assigned to the size estimates. Particle 


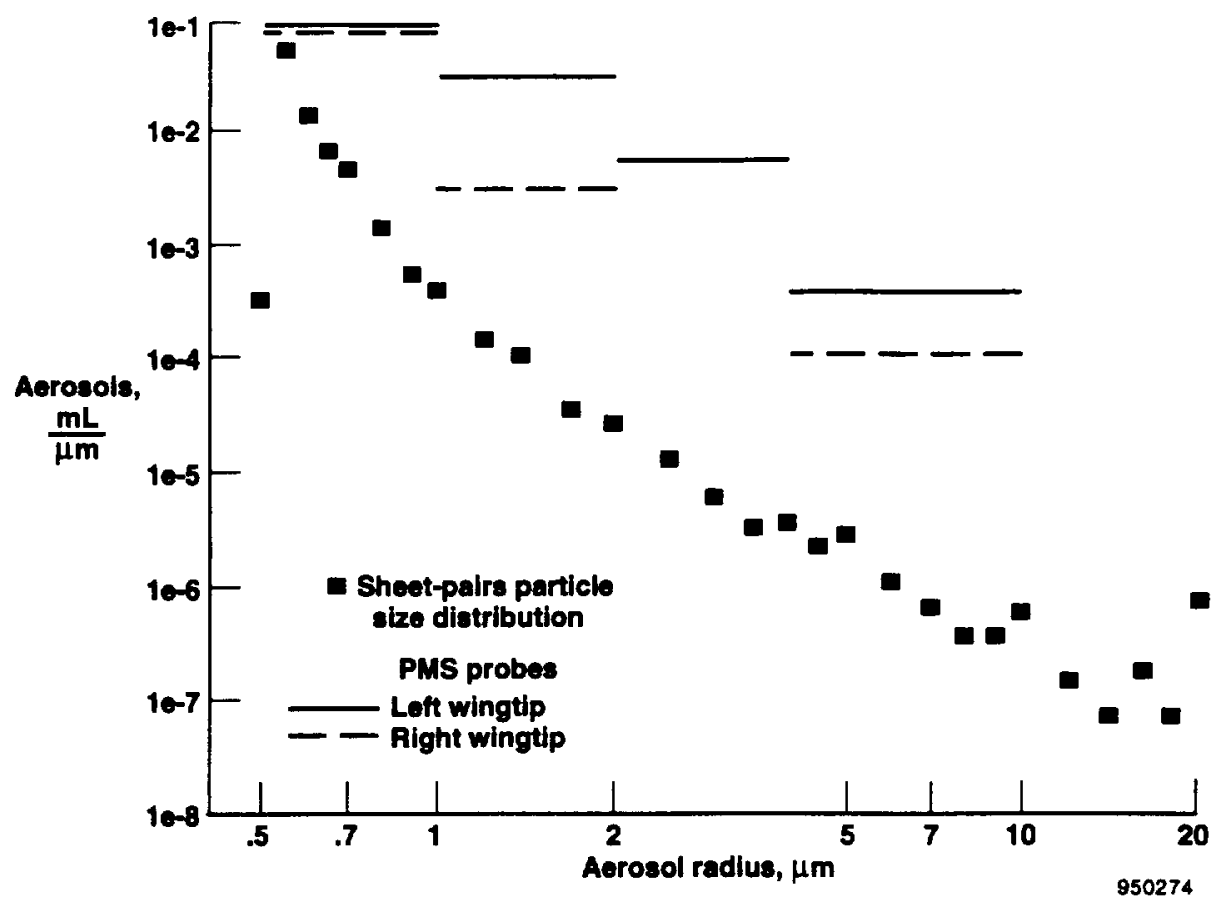

Figure 16. Comparison of sheet-pairs and PMS concentration measurements.

concentration values are relative and are calculated for sheet-pairs system as if data acquisition continued for the entire update period. This is not the case. Although feasible, correction to true values would require changes to the data processing software to provide the additional information needed.

\section{Problems and Lessons Learned with the Sheet-Pairs System}

The instrumentation flown on the DC-8 airplane has two operational modalities. The original design was optimized for velocity. Its use for particle analysis is a compromise which could be substantially improved with further software changes and rearrangement of the data output, presentation format, and rate capacity. These changes were beyond the scope and funding of this work. Nonetheless, this system has demonstrated technology potential for sheet-pair airspeed and particle measurements in flow outside the airplane boundary layer and undisturbed by the measurement apparatus.

For the sheet-pairs system, velocity measurements were obtained almost all of the time, even when particles were sparse. Velocity measurements corresponded well with DADS airdata. Particle concentration trends from the sheet-pairs system were in reasonable agreement with the PMS measurements. Absolute values were not in agreement because of a reduced sampling time window.

\section{FLIGHT TEST SUMMARY}

The results from these flights clearly demonstrate the usefulness of the DC- 8 aircraft as a testbed for flight evaluation of optical measurement concepts at the breadboard or brassboard stage of maturity. The aircraft test stations afforded ample room for adjusting the experiment set-up to optimize performance. The benign environment in the DC-8 aircraft minimized the need for hardening experiments to survive and operate in the flight environment. Vibration was the only identified environmental factor that caused difficulty in flight. Note, however, that the presence of vibration, a universal situation for the flight environment, offered a real-world challenge to the experimenters that was effectively countered. The presence of multiple experiments with different designs allowed rapid cross-checking of unexpected results with other experiments acquiring similar information. 


\section{Optical Measurement Potential}

The potential for using optical systems for measuring airspeed and aerosol characteristics has clearly been demonstrated on these flight tests. Airspeed was measured by all three systems for a substantial portion of the flight time. For the Doppler-concept systems, optically derived airspeed was in excellent correlation with the airspeed measured by the standard pitot-static system on the aircraft. This result suggests that the availability of natural aerosols may provide sufficient optical backscatter for similar systems to be used at altitudes up to $40 \mathrm{kft}$. Potential exists for use at HSCT cruise altitudes in the lower stratosphere where the aerosol populations are somewhat more prevalent and more stable over long periods of time.

Two of the systems measured aerosol characteristics. The sheet-pairs system assessed the characteristics of individual particles with the results showing qualitative correlation with the independent PMS on the aircraft. The results from the pulsed Doppler lidar system provided an optical backscatter measurement that was in good agreement with values obtained from the PMS.

\section{Flight Scheduling}

Having several days available between the first and second flights to allow troubleshooting and system verification to take place was useful. The time allotted to the series of tests proved to be adequate for the task of assessing the performance of optical airspeedsensing systems. Although additional time could have been used, it is doubtful that the new information obtained would have materially changed the results and conclusions.

\section{Common Database Format}

Before starting the flight test, coordinating of data formatting among the experimenters to create a common database would have been extremely useful. Comparing data among experimenters has been limited because of the lack of a common format.

\section{CONCLUDING REMARKS}

Optical airspeed measurement has broad applications particularly for highly maneuverable aircraft for which pitot-static systems pose serious limitations during unusual attitudes. Doppler techniques also provide low airspeed measurements for rotorcraft. Higher power systems offer the possibility for remotely detecting turbulence with application to gust alleviation and avoiding engine inlet unstart for military and civilian supersonic aircraft. This DC-8 test sequence has provided early validation of these concepts over the atmospheric altitude range expected to contain the most challenging measurement conditions in terms of optical backscatter.

Although further work is needed, these preliminary results suggest that the optical airspeed measurement concepts are viable for DC-8 test altitudes and beyond. Further work is required to probe the flight envelope over which the optical airspeed measurement can be used. Operation during inclement weather should be investigated. The effects of shock waves on the measurement concept should be assessed. Probably the most important item of further investigation includes the characterization of the lowest naturally occurring atmospheric backscatter conditions to identify system requirements and to assess the potential for world-wide operations with acceptably low probability of system failure.

\section{ACKNOWLEDGMENTS}

The assistance of Mr. Richard Richmond, USAF Wright Aeronautical Laboratories, Dayton, Ohio, in providing the $2-\mu \mathrm{m}$ laser system used by the pulsed Doppler lidar in this series of tests is gratefully acknowledged. The assistance of Mr. Steve Hynes, Naval Surface Warfare Center, Warminster, Pennsylvania, in providing the $1-\mu \mathrm{m}$ laser system used by the continuous wave Doppler lidar in these tests is greatly appreciated.

The participation and assistance received from the Atmospheric Physics Research Branch, NASA Ames Research Center, Mountain View, California, is gratefully acknowledged. In particular, the assistance of Dr. Rudolf Pueschel, Mr. Steven Howard, and Mr. Guy Ferry from this organization is noted. The DC-8 Aircraft Manager, Mr. John Reller of the Medium Altitude Missions Branch at Ames facilitated the flight operation and assured that the aircraft operation and performance were responsive to the needs of 
the experimenters. His help is appreciated and gratefully acknowledged.

\section{REFERENCES}

[1] Medium Altitude Missions Branch Ames Research Center, Moffett Field, California, $D C-8$ Airborme Laboratory Experimenters Handbook, June 15, 1994.

[2] Smart, A. E., "Optical Velocity Sensor for Airdata Applications," Optical Engineering, vol. 31, no. 1, Jan. 1992, pp. 166.

[3] Smart, A. E., "Velocity Sensor for an Airborne Optical Airdata system," Journal of Aircraft, vol. 28, no. 3, Mar. 1991, pp. 163-164.

[4] Erwin, L. L., McGann, R. L., Soreide, D. C., and Morris, D. J., "Enhanced Mode Lidar for Airborne Airspeed Measurement," Seventh Conference on Coherent Laser Radar Applications and Technology, Paris, France, July 19-23, 1993.

[5] McGann, R. L., Caldwell, J. A., Hilton, S. M., and Soreide, D. C., Three-Component LIDAREnhanced LDV Flow Diagnostics System, AIAA 94-2646, June 20-23, 1994.

[6] Sonnenschein, C. M. and Horrigan, F. A., "Signal-to-Noise Relationships for Coaxial Systems that Heterodyne Backscatter from the Atmosphere," Applied Optics, vol. 10, no. 7, July 1971 , pp. 1600+.

[7] Jenson, L. and Menton, R. K., "Evaluation Tests for an LDV Signal Processor," Laser Anemometry-Advances and Applications: 3rd International Conference, Swansea, Wales, Sept. 2629,1989 , pp. 3457-3492.
[8] Kmetec, J. D. et al., "Diode-Pumped 2- $\mu \mathrm{m}$ Coherent Laser Radar," Conference on Lasers and Electro-Optics, 1993, vol. 11, OSA Technical Digest Series (Optical Society of America, Washington, D.C., 1993), p. 46.

[9] Shannon, D. et al., "Fundamental-Mode 2- $\mu \mathrm{m}$ Solid-State Laser End-Pumped with 80 W Fiber Coupled GaAlAs Laser Diode Emission," Conference on Lasers and Electro-Optics, 1992, vol. 12, OSA Technical Digest Series (Optical Society of America, Washington, D.C., 1992), p. 20.

[10] Mocker, H. W. and Wagener, T. J., "Laser Doppler Optical Airdata System: Feasibility Demonstration and Systems Specifications," Applied Optics, vol. 33, no. 27, Sept. 1994, pp. 64576471.

[11] Munoz, R. M., et al., "Airborne Laser Doppler Velocimeter," Applied Optics, vol. 13, no. 12, Dec. 1974, pp. 2890-2898.

[12] Post, M. J., "Aerosol Backscattering Profiles at $\mathrm{CO}_{2}$ Wavelengths: The NOAA Database," Applied Optics, vol. 23, no. 15, Aug. 1984, pp. 2507-2509.

[13] Hughes, A. J. and Pike, E. R., "Remote Measurement of Wind Speed by Laser Doppler Systems," Applied Optics, vol. 12, no. 3, Mar. 1973, pp. 597-601.

[14] van de Hulst, H. C., Light Scattering by Small Particles, Wylie \& Sons, New York, 1957. 
Pubic reporting burden for this collection of intormation is estimaled to average 1 hour per response. inciuding the time tor reviewing instructions. searching existing oata sources, gathering and maintaining the data needed, and completing and reviewing the collection of intormation. Send comments regarding this buroen estimale of any other aspect of this collection of information.

inciuding suggestions for reducing this burden, to Washington Headquarters Services. Directorate for Intormation Operations and R
VA 22202-4302. and to the Otfice of Management and Budget, Paperwork Reduction Project (0704-0188), Washingtori. DC 20503.

\begin{tabular}{|l|l|l|l}
\hline 1. AGENCY USE ONLY (Leave blank) & $\begin{array}{c}\text { 2. REPORT DATE } \\
\text { July } 1997\end{array}$ & $\begin{array}{l}\text { 3. REPORT TYPE AND DATES COVERED } \\
\text { Technical Memorandum }\end{array}$ \\
\hline
\end{tabular}

4. TITLE AND SUBTITLE

Comparative Optical Measurements of Airspeed and Aerosols on a DC-8 Aircraft

6. AUTHOR(S)

WU 529502400 RR 00000

Rodney Bogue, Rick McGann, Thomas Wagener, John Abbiss, and Anthony Smart

7. PERFOAMING ORGANIZATION NAME(S) AND ADDRESS(ES)

B. PERFOAMING ORGANIZATION

REPORT NUMBER

NASA Dryden Flight Research Center

P.O. Box 273

H-2189

Edwards, Califomia 93523-0273

9. SPONSORINGNONITORING AGENCY NAME(S) AND ADDRESS(ES)

10. SPONSORINGMONITOAING

AGENCY REPORT NUMBER

National Aeronautics and Space Administration

Washington, DC 20546-0001

NASA TM-113083

11. SUPPLEMENTARY NOTES

Presented at the 16th International Congress on Instrumentation in Aerospace Simulation Facilities, Wright-

Patterson AFB, Dayton, Ohio, July 17-21, 1995.

12a. DISTRIBUTIONAVAILABILTY STATEMENT

12b. DISTRIBUTION CODE

Unclassified-Unlimited

Subject Category 06

13. ABSTRACT (Maximum 200 words)

NASA Dryden supported a cooperative flight test program on the NASA DC-8 aircraft in November 1993. This program evaluated optical airspeed and aerosol measurement techniques. Three brassboard optical systems were tested. Two were laser Doppler systems designed to measure free-stream-referenced airspeed. The third system was designed to characterize the natural aerosol statistics and airspeed. These systems relied on optical backscatter from natural aerosols for operation. The DC-8 aircraft carried instrumentation that provided real-time flight situation information and reference data on the aerosol environment. This test is believed to be the first to include multiple optical airspeed systems on the same carrier aircraft, so performance could be directly compared. During $23 \mathrm{hr}$ of flight, a broad range of atmospheric conditions was encountered, including aerosol-rich layers, visible clouds, and unusually clean (aerosol-poor) regions. Substantial amounts of data were obtained. Important insights regarding the use of laser-based systems of this type in an aircraft environment were gained. This paper describes the sensors used and flight operations conducted to support the experiments. The paper also briefly describes the general results of the experiments.

14. SUBJECT TERMS

Aerosols, Aircraft instrumentation, Airspeed indicators, Laser optical radar 29

16. PRICE CODE $\mathrm{AO} 3$

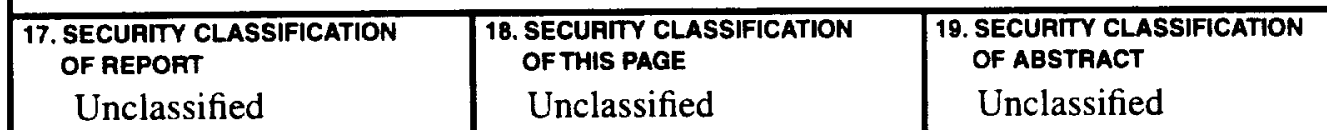

NSN 7540-01-280-5500

Available from the NASA Center for AeroSpace Information, 800 Elkridge Landing Road,

Linthicum Heights, MD 21090; (301)621-0390

20. LIMTTATION OF ABSTRACT

Unlimited

Standard Form 298 (Rev. 2-89)

Prascribed by ANSI SId. 239918 